\title{
Production Planning and Control
}

\section{Supplier selection and supply chain configuration in the projects environment}

\author{
Article information: \\ Post-Print version \\ Yasmine Sabri*a , Guido J.L. Micheli ${ }^{\mathrm{b}}$, Enrico Cagno ${ }^{\mathrm{b}}$ \\ ${ }^{a}$ Aston Logistics and Systems Institute, Aston University, Birmingham, United Kingdom \\ bepartment of Management, Economics and Industrial Engineering, Politecnico di Milano, Milan, Italy
}

To cite this article:

Yasmine Sabri, Guido J. L. Micheli \& Enrico Cagno (2020): Supplier selection and supply chain configuration in the projects environment, Production Planning \& Control, DOI:

$10.1080 / 09537287.2020 .1853269$

https://doi.org/10.1080/09537287.2020.1853269

\author{
Yasmine Sabri* \\ Aston Logistics and Systems Institute \\ Engineering Systems and Supply Chain Management Group \\ Aston University \\ Birmingham, B4 7ET, UK \\ y.sabri@aston.ac.uk
}




\section{Supplier selection and supply chain configuration in the projects environment}

Suppliers in the Engineering-Procurement-Construction (EPC) projects environment are often qualified based on their annual turnover and cash flow; such practice results in the exclusion, at a preliminary stage, of a relatively large number of small suppliers from the approved vendors' list of EPC contractors, eventually pushing them out of the market. This research examines the suitability of applying a broader perspective for supplier selection in the projects environment to facilitate the provision of an inclusive evaluation of the different capabilities of suppliers.

Supply chain configuration has significant importance in developing a strategic approach for supplier selection, yet with little exploration in the projects environment. Reviewing the literature has resulted in identifying the level of localisation/globalisation, collaboration and partnerships as the most relevant elements of supply chain configuration in the projects environment. Through collecting empirical evidence from 20 EPC suppliers and 6 contractors, this research investigates whether supply chain configuration settings can offset the potential implications of a modest financial fitness, and hence, may improve a supplier's opportunity to get selected.

Supply chain configuration is put forward as a capability, the development of which contributes to the improvement of the supply network, and so should be reflected in the supplier selection criteria in projects' environments. Furthermore, this research puts forwards a framework identifying four potential zones which pinpoint the conditions by which suppliers can update their supply chain configuration.

This research offers guidelines for EPC contractors which wish to adopt an all-encompassing versatility approach in supplier selection, and guides suppliers and supply chain researchers to consider the supply chain (re-)configuration as a proactive plan for the survival of suppliers which operate in global high-uncertainty environments.

Keywords: supplier selection, supply chain configuration, collaboration, partnerships, globalisation, projects environment. 


\section{Introduction}

Supplier selection is an antecedent to a project's success; however, oftentimes the selection criteria are ambiguous due to high uncertainty and intense competition (Watt et al., 2010). Supplier selection as a strategic decision (Ellram, 1990; Wetzstein et al., 2016) is considered crucial in enhancing the competitiveness of buyer firms (de Boer et al., 2001; Mukherjee, 2014), where supplier capabilities contribute to establishing a buyer's corresponding competitive advantage (Koufteros et al., 2012). Buyers in highly-competitive markets usually consider the financial capacity and economies of scale of suppliers as the main determinant in supplier selection decisions (Badorf et al., 2019), which points to a potential disconnect between supply chain performance indicators, which focus on fulfilment and integration, and supplier selection criteria, which focus on financial capacity (Behera et al., 2015). A striking example of such practice is the Italian supply market for the EPC (Engineering-Procurement-Construction) projects, which traditionally have held international recognition in this domain. However, due to a continuous lack of governmental support and the fierce competition from low-cost countries, many of these suppliers lost their market shares and eventually went completely out of business or were acquired by larger firms (Brancaleoni, 2015; UCC-ANIMA, 2011). Currently, a large number of suppliers are at the risk of continuation of this trend, as even more suppliers are expected to lose their businesses in the coming years.

The idiosyncrasy of supply chains in the projects environment is in offering highly-customised products, as such manufacturing costs and lead times can be higher due to low volumes, making the supply chain more vulnerable to risks and uncertainties (Hicks et al., 2000; Micheli, 2008). Project owners can be directly involved in supplier selection, as the decoupling point is in the engineering phase (Gosling and Naim, 2009); hence, adversarial bargaining is a common practice (Behera et al., 2015). The supply market to EPC projects is complex and competitive (Watt et al., 2010), where suppliers are expected to deliver according to rigid scheduling and shorter lead times. Moreover, the size-asymmetry between EPC contractors and their suppliers increases the relationship uncertainty and lowers the probability of trust being built between the supply chain members (Lee and Johnsen, 2012; Villena and Craighead, 2017).

Early literature has emphasised using multiple qualitative as well as quantitative criteria for strategic supplier selection (de Boer et al., 2001), and suggested that price and financial capability should be among the least important selection criteria (Choi and Hartley, 1996). In doing so, buyers 
can ensure long-term stability and establish collaborative relationships with key suppliers (Ellram, 1990) - an approach seldom adopted in the Italian EPC projects environment. In practice, the decisions on supplier selection in such environments are based on a supplier's financial performance and technical capacity. This may result in buyers overlooking that focusing on finance-specific supplier selection criteria only serves their competitive pricing rather than enhancing the buyer's innovation or quality capabilities (Koufteros et al., 2012). As such, the buyer-supplier relationship may not offer a sustained competitive advantage to both parties. To mitigate these grave implications, adopting a broader set of supplier selection criteria is recommended (Choi and Hartley, 1996; de Boer et al., 2001; Hsu et al., 2006).

Supply chain configuration (i.e. level of globalisation/localisation, collaboration and partnerships) has gained significant importance in developing a strategic approach for supplier selection (Ellram, 1990) and managing supply risk (Micheli et al., 2008), yet it has received less attention in the engineer to order and wider projects supply chain literature. The literature has provided insights into the individual constituents of supplier selection criteria (Choi and Hartley, 1996; Hsu et al., 2006; Masi et al., 2013; Behera et al., 2015; Chen et al., 2018; Badorf et al., 2019), but a comprehensive analysis that considers supplier selection and supply chain configuration is still missing. Not surprisingly, there is a paucity of research that considers the inter-organisational relationships of Small- and Medium-sized Enterprise (SME) (Palomero and Chalmeta, 2014) or the implications of size-asymmetry between buyers and suppliers for the supplier selection process (Lee and Johnsen, 2012), where varied approaches for supplier selection that simultaneously consider multiple dimensions are scant in EPC supply chains (Masi et al., 2013).

The present research extends this stream of research by exploring whether, and how, the variation in suppliers' level of localisation/globalisation, collaboration and partnerships may affect their chances of being approved by buyers. To maintain a balanced investigation, we conducted semi-structured interviews with 20 suppliers and 6 EPC contractors. In this study, EPC projects are defined as large-scale oil and gas projects managed by EPC contractors and systems integrators that are mostly huge multinational firms which possess world-class project management skills as well as the technical capacity to run complex capital non-repetitive projects.

The analyses provided here collectively assist in devising proactive survival plans for suppliers in the face of the heightened levels of uncertainty and stiff global competition. The research offers 
a broader perspective for supplier selection in the high-uncertainty projects environment, which can be used by EPC practitioners to (re)evaluate their supplier selection approaches and compare the suitability of these approaches with the composition and nature of their supply base.

\section{Theoretical background}

\section{Supplier selection in the projects environment}

Supplier selection is a context-specific strategic decision that contributes to creating sustainable competitive advantage (Ellram, 1990; Hsu et al., 2006). Adopting a broad set of qualitative and quantitative supplier selection criteria is recommended in multiple early works (Choi and Hartley, 1996; de Boer et al., 2001; Hsu et al., 2006). The literature has also pointed to a potential divide between supplier selection criteria, which focus on financial capacity and economies of scale, and supply chain performance indicators, which focus on fulfilment, integration and collaboration (Behera et al., 2015). Moreover, buyer firms should consider that the capabilities of suppliers contribute in developing the corresponding capabilities of the buyer firms themselves, but not the buyers' overall portfolio of capabilities (Koufteros et al., 2012). As such, selecting a supplier based on financial capability may serve only the competitive pricing of the buyer, and does not necessarily enhance innovation or quality capabilities (Koufteros et al., 2012).

The supplier selection process, therefore, needs to use a broad range of criteria to facilitate the provision of an inclusive evaluation of various supplier capabilities (Hsu et al., 2006; Micheli et al., 2008) which are crucial in achieving critical project goals and success (Chen et al., 2018; Aloini et al., 2015). Mainly considering tangible criteria such as cost may result in less impact on enhancing a buyer's performance as compared to when intangible ones are considered (e.g. honest communication, willingness to share critical information, and ability to build relationships) (Hsu et al., 2006). Many of the suppliers in the projects environment are small and medium-sized, buyersupplier size-asymmetry does not always play in the favour of suppliers, since buyers perceive the relationship as less beneficial when they deal with small suppliers, and the latter may experience more buyer opportunism (Villena and Craighead, 2017). Furthermore, a number of factors related to the impact on the project, including cost minimisation and economic-and-legal-based attributes, influence the supplier selection process (Masi et al., 2013). These practices contribute to making projects supply chains suffer from structural fragmentation (Gosling et al., 2015) and increase risks and uncertainty (Aloini et al., 2015). Some concerns have thus been raised regarding the feasibility 
of supplier full integration in such environments (Ireland, 2004; Gosling and Naim, 2009; Gadde and Dubois, 2010), as the projects industry norms lean towards exploitation rather than partnering (Gadde and Dubois, 2010), and buyer-supplier size-asymmetry increases the relationship vulnerability (Lee and Johnsen, 2012).

Koufteros et al. (2012) found a correlation between cost-based supplier selection and the prevalence of arm's length-type relationships, while collaborative relationships are a result of a supplier selection process that considers multiple supplier capabilities. Lack of trust and collaboration can lead to inefficiencies and poor performance (Hsu et al., 2006). Hence, supply chain configuration - with its collaboration, partnering and level of globalisation dimensions emerges as an important factor that needs to be addressed when investigating supply chains in the projects environment.

\section{Supply chain configuration}

Supplier growth can be enhanced by considering how supply chains are configured (Lee, 2002; Corominas et al. 2015). Supply chain configuration contributes to achieving and sustaining competitive performance (van der Vaart and van Donk, 2008; Prajogo et al., 2016). This is particularly so in projects and contracting environments (Chen et al., 2018), where enhancing interorganisational relationships is inevitable for many businesses if they are to survive the global market competition (Simatupang and Sridharan, 2002; Barrat, 2004; Goffin et al., 2006; Chan and Prakash, 2012; Youn et al., 2013).

Configuration research is rooted in the idea of establishing an integrated supply chain that provides added value to the end customer and preserves a firm's competitiveness (Fisher, 1997). Lee (2004) suggested that the best supply chains are neither the fastest nor the most cost-efficient; rather, the best are those which can be agile, adaptable, and aligned. Aitken et al. (2005) extended Lee's (2004) work by suggesting a 'leagile' supply chain configuration, the upstream of which is lean (i.e. cost-efficient) and downstream is agile (i.e. responsive). Since the seminal work of Fisher (1997), there has been a growing interest in customising the configuration so that it suits the supply chain's contextual environment. Hence, it is important to take into account key factors such as level of localisation and globalisation (Ebben and Johnson, 2005; Bhatnagar and Sohal, 2005; Kirca et al., 2012), which was found to have a major influence on supply chain performance (Sabri et al., 2017). 
Supply chain configuration is usually conceptualised in terms of several structural elements, such as the number of actors within the chain, geographical dispersion level, collaboration and inter-organisational relationships, and supply and distribution network design (Chandra and Grabis, 2007; Sezen, 2008; Chopra and Miendle, 2012; Corominas et al., 2015). As such, the configuration deals with the coordination of products, processes, and logistics decisions (Zheng et al., 2010). Supply chain configuration can be developed based on one of three approaches; product characteristics, process, or systems thinking (Sabri et al., 2017).

Supply chains in the projects environment are composed of three main phases: (i) tendering and contracting, (ii) product development and engineering, and (iii) product realisation (Mello et al., 2015). The core of such supply chains is contractual inter-organisational relationships that involve tendering activities (Ruuska et al., 2013; Behera et al., 2015) where supply chain collaboration and partnering gains high importance when it comes to decreasing demand uncertainty (Gosling and Naim, 2009). Extant literature has provided beneficial insights into the different dimensions of enhancing supply chain relationships by having a joint project management office (Eriksson, 2010) and establishing buyer-supplier joint-action integration (Eriksson and Pesamaa, 2013). Trust, integration, information sharing and the relational behaviour are antecedents of managing supply chains in the projects environment (Aloini et al., 2015).

In light of this discussion, supply chain configuration can be conceptualised using various constituents and approaches. This research takes the view that the most relevant elements of supply chain configuration to the projects environment are: collaboration, partnering, and the level of localisation/globalisation. This research also draws on systems thinking approach to supply chain configuration, with its focus on integration it has proved to be the most suitable perspective for the present research.

\section{Collaboration, partnering and localisation/globalisation in the projects environment}

Inter-organisational relationships are pertinent in the supply chain domain because firms can maximise their profitability as a result of the relational exchanges (Nyaga et al., 2010; Kache and Seuring, 2014). We have witnessed a shift in the nature of inter-organisational buyer-supplier relationships from being merely transactional to relationship-orientated, and focused on mutual benefits (Hsu et al., 2006; Omar et al., 2012). Supplier performance is therefore considered a key determinant of the overall supply chain's competitive performance, in which the most successful businesses are those that "... have carefully linked their internal processes to external suppliers 
and customers in unique supply chains ..." (Frohlich and Westbrook, 2001, p.185). In prior research, considerable attention has been paid to suppliers' performance (e.g. Tan et al., 1998; Micheli, 2008; Omar et al., 2012), and said research has attributed gains/losses in the upstream supply chain performance to gains/losses in the downstream side of the supply chain (Hsu et al., 2006; Fabbe-Costes and Jahre, 2008; Prajogo et al., 2016). Identifying how suppliers can act collaboratively and proactively to survive high-uncertainty environments of the new global market settings becomes more significant when the suppliers are small and medium businesses (Kumar and Singh, 2017).

A synthesis of collaboration and partnerships conceptualisation in the literature is presented and nine conceptualisation dimensions are identified in Table 1. Supply chain collaboration involves designing relevant activities for the involved parties, governing and maintaining the relationship (Matopoulos et al., 2007), where businesses manage the relationship structure and technology deployment that facilitates the success of the exchanges, considering the material, financial and information flows (Holimchayachotikula et al., 2014; Alfalla-Luque et al., 2013). Collaborative supply chains use collaborative performance systems and synchronise the decision-making of their members (Soosay and Hyland, 2015). Collaboration contributes to managing supply risks and enhancing profitability in supply chains in the projects environment (Micheli et al., 2008), thus leading to better decision-making by enhancing interface and trade-offs management (Gosling et al., 2015), which results in achieving the supply chain's objectives (Kim and Nguyen, 2018). Collaborative activities can be operationalised as; communication and conflict resolution, coordination of work and planning (Spekman, 1988), trust, information exchange, managing change, and cross-functional teams (Barratt, 2004; Aloini et al., 2015), coordinated ordering decisions (Chen et al., 2018), and assigning a facilitator and arranging team-building events (Eriksson, 2010). Project performance is dependent on supply chain collaborations, particularly in establishing the teamwork and mechanisms for problem resolution (Kim and Nguyen, 2018). The scope of these collaborative activities can be between supply chain members (vertical), among competitors and other organisations (horizontal), and lateral - i.e. a mixed strategy including both vertical and horizontal (Barratt, 2004; Chan and Prakash, 2012).

Partnerships are viewed as strategic inter-organisational relationships (Goffin et al., 2006; Lambert et al., 1996) that result in potential benefits, such as reducing project costs, increasing productivity and quality, and offering greater stability in uncertain conditions (Gadde and Dubois, 
2010); hence, they are particularly significant in uncertain industrial structures since they help buyers and suppliers to build social capital, increase investment, and decrease risks and uncertainties (Mentzer et al., 2000; Micheli et al., 2008; Koufteros et al., 2012). It therefore becomes relevant to investigate partnerships in the EPC projects environment with its extreme uncertainty levels.

Projects literature usually refers to achieving supply chain integration as partnering, which is manifested in establishing a joint project management office and IT platforms, in addition to joint action and cross-functional teams (Micheli et al., 2008; Gadde and Dubois, 2010; Eriksson, 2015). The construction industry institute defined partnership in projects as "long term commitment between two or more organisations for the purposes of achieving specific business objectives by maximizing the effectiveness of each participant's resources", and put forward eleven elements for partnering as follows: a) long-term relationship, b) commitment, c) continuous improvement, d) trust, e) investment, f) alignment, g) synergism, h) shared risks, i) mutual rewards, j) equity, k) systemic relationship and 1) competitive edge (CII, 1991-2019). Partnership with suppliers may determine whether a buyer will have access to scarce resources, and thus partner selection is key to partnership success (Koufteros et al., 2012).

Partnering has several dimensions; in the present research our interest is in the relationship strength dimension, defined as "...the extent to which integrative activities and technologies are utilised..." (Eriksson, 2015, p.40), which corresponds to the supply chain integration depth introduced in Frohlich and Westbrook (2001). The relationship strength dimension becomes significantly important when investigating inter-organisational relationships in the projects environment so as to avoid adversarial relationship patterns (Sariola and Martinsuo, 2015).

Partnering in projects' supply chains faces different challenges than in continuous manufacturing environments; these can be attributed to the complexity and uniqueness of the project, the fragmentation of its processes, a discontinuous uncertain demand, and a considerably larger supply base; hence, the relational exchanges often have lower transactional frequency (Eriksson, 2010; Aloini et al., 2015; Eriksson, 2015). As such, strategic partnerships can be difficult to attain or maintain in projects environments, since the supply chains are project-centred, and this temporality hampers the involved parties when it comes to reaping the benefits of the relationship in the long-term (Gadde and Dubois, 2010). Partnerships are often considered strategic, whereby they are dependent on establishing closer ties and sharing strategic resources 
and risks among the supply chain members as part of long-term strategic initiatives (Spekman, 1988; Lambert et al., 1996). Strategic partnerships involve mutual commitment and trust, joint decision-making, and a common strategic mindset towards the relationship. They are implemented in different dimensions, of which the most relevant are: top management support, information sharing and technology utilisation, joint performance measures, asset-specificity and strategic cross-functional teams (Youn et al., 2013; Mentzer et al., 2000). Partnerships are regarded as hybrid governance structures of bilateral relational exchanges with a credible commitment between the parties. Put simply, partnerships serve as a governance mechanism in which both parties lose if the relationship ends (Nyaga et al., 2010).

Lambert et al. (1996) and Goffin et al. (2006) pointed out a potential confusion in defining partnerships. Three dimensions were identified to distinguish between inter-organisational relationships: i) number of transactions, ii) longevity, and ii) level of closeness (Goffin et al., 2006). For the sake of the clarity of the present research, we embrace the notions presented in Nyaga et al. (2010) and Eriksson (2015), specifically that partnering is equivalent to full integration, as it must involve trust, top management commitment, close ties and joint decisionmaking based on a long-term perspective. Whilst collaboration can be long- or short-term, strategic partnerships usually extend to a long-term perspective. Furthermore, collaborative activities are implemented with a majority of suppliers, but partnering must be with a few carefully selected suppliers (Lambert et al., 1996; Gadde and Dubois, 2010; Koufteros et al., 2012). Collaborative activities stem from certain coordination mechanisms, whilst strategic partnership usually involves developing social capital and interpersonal relationships. This is particularly relevant to the Italian market, where supplier qualification is based on enhanced interpersonal relationships, which encourages supply chain members to foster closer relationships.

Enhancing trust, partnerships and collaboration is significant in projects supply chains to decrease opportunistic behaviour (Koufteros et al., 2012, Sariola and Martinsuo, 2015). However, they might fail to achieve results due to the lack of a common vision and joint goals; therefore, businesses may start viewing the supply chain as individual functions rather than an extended enterprise of interconnected firms. This functional focus may result in disconnecting demand data from supply data. It may also result in the uneven distribution of benefits and relationship disparity (i.e., when the relationship costs exceed its benefits), lack of consistency of the performance measures, failure to identify who to collaborate with (partner scarcity), and lack of trust and 
leadership commitment among the supply chain members (Barratt, 2004; Nyaga et al., 2010; Eriksson and Pesamaa, 2013; Fawcett et al., 2015). Hence, businesses need to establish a portfolio of relationships to avoid over-dependence (Gadde and Dubois, 2010).

Moreover, globalisation (as in Ebben and Johnson, 2005; Bhatnagar and Sohal, 2005; Kirca et al., 2012; with the evidence of the impact of its level on the performance of different supply chains as in Sabri et al., 2017), implies often geographically-dispersed international supply chains with suppliers located in different countries - a feature rather typical for EPC contractors, that operate for global customers in a naturally global geographic dispersion - which, in turn, may involve negative implications for firm performance in terms of service level reduction and cost rise due to increased supply chain complexity (Lorentz et al., 2012; in terms of practical evidence, the preliminary implications of COVID-19 on supply chains, before it has become a global disruption, have been widely debated). 
Table 1. Collaboration and partnerships in literature

\begin{tabular}{|c|c|c|c|}
\hline & Collaboration & Partnership & Sample Contributions \\
\hline Activities & $\begin{array}{l}\text { Coordination of work and } \\
\text { planning, trust, information } \\
\text { exchange, managing } \\
\text { change, and cross- } \\
\text { functional teams, } \\
\text { communication and conflict } \\
\text { resolution }\end{array}$ & $\begin{array}{l}\text { Joint decision-making, } \\
\text { common strategic mindset, } \\
\text { joint project management } \\
\text { office, collaborative IT } \\
\text { platforms, joint action and } \\
\text { cross-functional teams, sharing } \\
\text { strategic resources and risks, } \\
\text { mutual commitment and trust, } \\
\text { joint performance measures, } \\
\text { asset-specificity }\end{array}$ & $\begin{array}{l}\text { Collaboration: Spekman, 1988; } \\
\text { Barratt, 2004; Matopoulos et al., } \\
\text { 2007; Chan and Prakash, 2012; } \\
\text { Soosay and Hayland, 2015; Kim } \\
\text { and Nguyen, 2018. } \\
\text { Partnership: Eriksson, 2015; } \\
\text { Mentzer et al., 2000; Goffin et al., } \\
\text { 2006; Lambert et al., 1996; } \\
\text { Spekman, 1988; Youn et al., 2013; } \\
\text { Nyaga et al., 2010; Koufteros et al., } \\
\text { 2012; CII, 1991-2019 }\end{array}$ \\
\hline Closeness & Arm's length or Close & Close (full integration) & $\begin{array}{l}\text { Collaboration: Goffin et al., 2006; } \\
\text { Lambert et al., 1996; Matopoulos et } \\
\text { al., 2007; Soosay and Hayland, } \\
\text { 2015; Kim and Nguyen, } 2018 \\
\text { Partnership: Goffin et al., 2006; } \\
\text { Lambert et al., 1996; Spekman, } \\
\text { 1988; Mentzer et al., 2000; Barratt, } \\
\text { 2004; Eriksson, 2015; CII, 1991- } \\
2019\end{array}$ \\
\hline Longevity & Short-term or Long-term & Long-term & $\begin{array}{l}\text { Collaboration: Goffin et al., 2006; } \\
\text { Lambert et al., 1996; Matopoulos et } \\
\text { al., 2007; Soosay and Hayland, } \\
\text { 2015; Kim and Nguyen, } 2018 \\
\text { Partnership: Goffin et al., 2006; } \\
\text { Lambert et al., 1996; Spekman, } \\
\text { 1988; Mentzer et al., 2000; Nyaga } \\
\text { et al., 2010; Koufteros et al., 2012; } \\
\text { CII, 1991-2019 }\end{array}$ \\
\hline $\begin{array}{l}\text { Relational } \\
\text { Transactions } \\
\text { Frequency and } \\
\text { Continuity }\end{array}$ & $\begin{array}{l}\text { Rare or Frequent } \\
\text { Discontinuous or } \\
\text { continuous }\end{array}$ & $\begin{array}{c}\text { Frequent } \\
\text { Continuous }\end{array}$ & $\begin{array}{l}\text { Spekman, 1988; Mentzer et al., } \\
\text { 2000; Eriksson, 2010; Gadde and } \\
\text { Dubois, 2010; Eriksson, 2015; } \\
\text { Aloini et al., 2015; CII, 1991-2019 }\end{array}$ \\
\hline $\begin{array}{l}\text { Relationship } \\
\text { Scope }\end{array}$ & $\begin{array}{c}\text { Operational } \\
\text { 'project by project' }\end{array}$ & $\begin{array}{l}\text { Strategic } \\
\text { 'systemic' }\end{array}$ & $\begin{array}{l}\text { Collaboration: Goffin et al., 2006; } \\
\text { Lambert et al., 1996; Spekman, } \\
\text { 1988; Mentzer et al., 2000; } \\
\text { Matopoulos et al., 2007; Alfalla- } \\
\text { Luque et al., 2013; } \\
\text { Holimchayachotikula et al., 2014; } \\
\text { Partnership: Goffin et al., 2006; } \\
\text { Lambert et al., 1996; Spekman, }\end{array}$ \\
\hline
\end{tabular}




\begin{tabular}{|c|c|c|c|}
\hline & & & $\begin{array}{l}\text { 1988; Mentzer et al., 2000; } \\
\text { Eriksson, 2010; Gadde and Dubois, } \\
\text { 2010; Eriksson, 2015; Aloini et al., } \\
\text { 2015; CII, 1991-2019. }\end{array}$ \\
\hline $\begin{array}{l}\text { Relationship } \\
\text { dynamics }\end{array}$ & $\begin{array}{l}\text { Relationship disparity or } \\
\text { parity }\end{array}$ & $\begin{array}{l}\text { Relationship parity, both } \\
\text { parties lose if the relationship } \\
\text { ends }\end{array}$ & $\begin{array}{l}\text { Collaboration: Spekman, 1988; } \\
\text { Barratt, 2004; Chan and Prakash, } \\
2012 . \\
\text { Partnership: Nyaga et al., 2010; } \\
\text { Koufteros et al., } 2012\end{array}$ \\
\hline $\begin{array}{l}\text { Parties and } \\
\text { industry } \\
\text { Atmosphere }\end{array}$ & $\begin{array}{c}\text { Few or many suppliers in } \\
\text { adversarial or collaborative } \\
\text { conditions }\end{array}$ & $\begin{array}{l}\text { Carefully selected few } \\
\text { suppliers in collaborative } \\
\text { conditions }\end{array}$ & $\begin{array}{l}\text { Lambert et al., 1996; Mentzer et al., } \\
\text { 2000; Hsu et al., 2006; Gadde and } \\
\text { Dubois, 2010; Koufteros et al., } \\
2012\end{array}$ \\
\hline Adaptation & Few & Mutual & $\begin{array}{l}\text { Gadde and Dubois, 2010; Aloini et } \\
\text { al., } 2015\end{array}$ \\
\hline Dependence & Avoided & Accepted & $\begin{array}{l}\text { Gadde and Dubois, 2010; Aloini et } \\
\text { al., } 2015\end{array}$ \\
\hline
\end{tabular}

\section{Research Design}

Considering the explorative nature of this study, the context specificity of supplier selection (Hsu et al., 2006) and supply chain configuration (Melnyk et al., 2014), we opt for a case-based approach, as it facilitates a comprehensive analysis of supply chain configuration, and makes it possible to explore the influence of the EPC projects environment (Yin, 2018). We position our research design in line with Ketokivi and Choi's (2014) definition of qualitative research as an approach that allows contextual interpretation of the meanings of concepts, rather than mere examination of the concepts' intensity or frequency. As such, the present research provides meaningful insights that could usefully be transferred to supply chains in other environments (Gibbert and Ruigrok, 2010).

This research draws on Yin's (2018) holistic multiple case study design and applies Patton's (1990) purposeful intensity sampling guidelines in selecting information-rich cases that manifest the phenomenon under study intensely but not extremely, and therefore the researcher has to establish considerable prior knowledge and judgement on the sample. Purposeful sampling was found particularly powerful in researching small and medium businesses, as it produces more homogenous samples (Palomero and Chalmeta, 2014). The intensity in this research is considered 
by means of two dimensions. Firstly, we sought to select cases of supply networks that are significant in the Italian EPC sector; as such, two EPC projects supply networks were identified as cases. The first deals with oil and gas valves and the second specialises in pressure equipment. These two supply networks were carefully chosen, as Italian suppliers count for approximately a quarter of the global production of oil and gas valves, and one-third of the global production of premium pressure equipment (Brancaleoni, 2015; UCC-ANIMA, 2011). The second intensity dimension is associated with the selection of suppliers that are already on the approved vendors' list, since these suppliers may be considered high performers in the EPC supply market.

To ensure rich dyadic data, the empirical evidence was drawn from examining the perspectives of both suppliers and EPC contractors (i.e. buyers) in each case. To ensure that our supplier sample followed the purposeful intensity sampling guidelines of exercising considerable judgement (Patton, 1990), we collaborated with the two main associations in Italy to identify best-in-class suppliers. The first is ANIMP, or 'Associazione Nazionale di Impiantistica Industriale' - an association for EPC contractors whose component suppliers mainly operate on a project basis with EPC contractors. The second is ANIMA, or 'Federazione delle Associazioni Nazionali dell'Industria Meccanica' - the Italian federation of national associations for the mechanical and engineering industries, which is an association comprising suppliers from different industries, one section of which is suppliers for EPC projects. Most of the Italian suppliers producing oil and gas valves and pressure equipment are registered with ANIMP, ANIMA, or both.

The consultation of ANIMP and ANIMA resulted in including 20 suppliers in the research sample, in addition to soliciting the views of 6 EPC contractors,. The suppliers are considered high performers in comparison to the entire pool of registered suppliers in ANIMP and ANIMA, and are included in the approved vendors' list of the six contractors.

\section{Data collection}

As shown in Figure 1, the suppliers belong to the two outlined cases; valve supply network (1) and pressure equipment supply network (2). The explorative nature of this research encouraged the inclusion of a large number of respondents (Patton, 1990); moreover, such a research design is in line with most qualitative studies investigating inter-organisational relationships that include a considerably large number of respondents; for example, Lambert et al. (1996) interviewed 60 respondents, while Goffin et al. (2006) interviewed 39, and Fawcett et al. (2015) interviewed 49. 
Similarly, in the projects environment context, Eriksson (2015) interviewed 50 respondents, and Gosling et al. (2015) interviewed 12 suppliers.

Figure 1. Research Sample

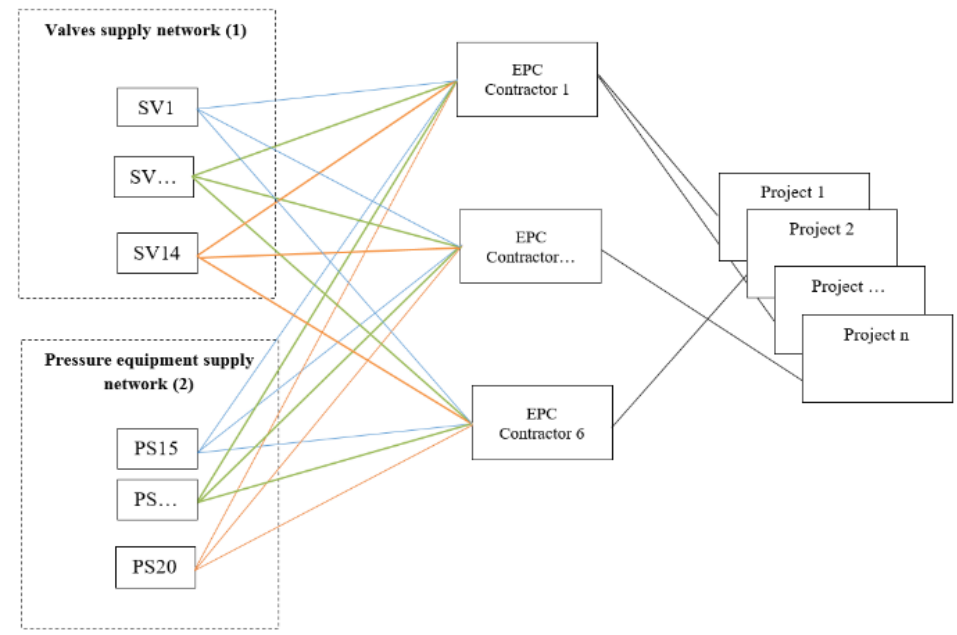

Data collection, as depicted in Figure 2, was performed in three steps. Firstly, ANIMP and ANIMA were contacted to collect data on the businesses registered in their lists as suppliers of special valves and pressure equipment for EPC contractors. Further information was also collected on what is considered the primary performance priorities that a supplier should satisfy to be listed as an approved vendor in the EPC sector in Italy. In parallel, a preliminary questionnaire was sent to 13 main EPC contractors to identify their supplier selection criteria, and determine which suppliers are on their approved vendors' lists for special valves and pressure equipment. Responses were received from eight EPC contractors, and six of them were willing to take part in this research. The interviews with the EPC contractors addressed their corporate and supply chain strategy, as well as their supplier selection process and procedure for adding a supplier to the approved vendors' list.

Secondly, the information received from ANIMP and ANIMA was cross-examined with the responses of the EPC contractors, based on which a consolidated list of 94 valves and 55 pressure equipment suppliers was developed, and of these 33 and 40 suppliers were high performers. Following the purposeful intensity sampling procedures (Patton, 1990; Palomero and Chalmeta, 2014) all high performer suppliers which were vendors approved by the indicated EPC contractors 
were invited to take part in the research; 14 valves suppliers and 6 pressure equipment suppliers showed willingness and agreed to be interviewed and included in our investigation.

In the third step, we interviewed key respondents from each supplier with involvement in the supply chain area. Each interview lasted between 60 and 90 minutes. Semi-structured interviews were conducted with the suppliers, during which qualitative and quantitative data was collected to answer the research question how do approved vendors/suppliers configure their supply chains in the EPC projects environment? Data was also collected from secondary sources such as company reports and websites, the ANIMP website, and complemented by reports and literature from national members of ANIMA.

Figure 2. Data Collection

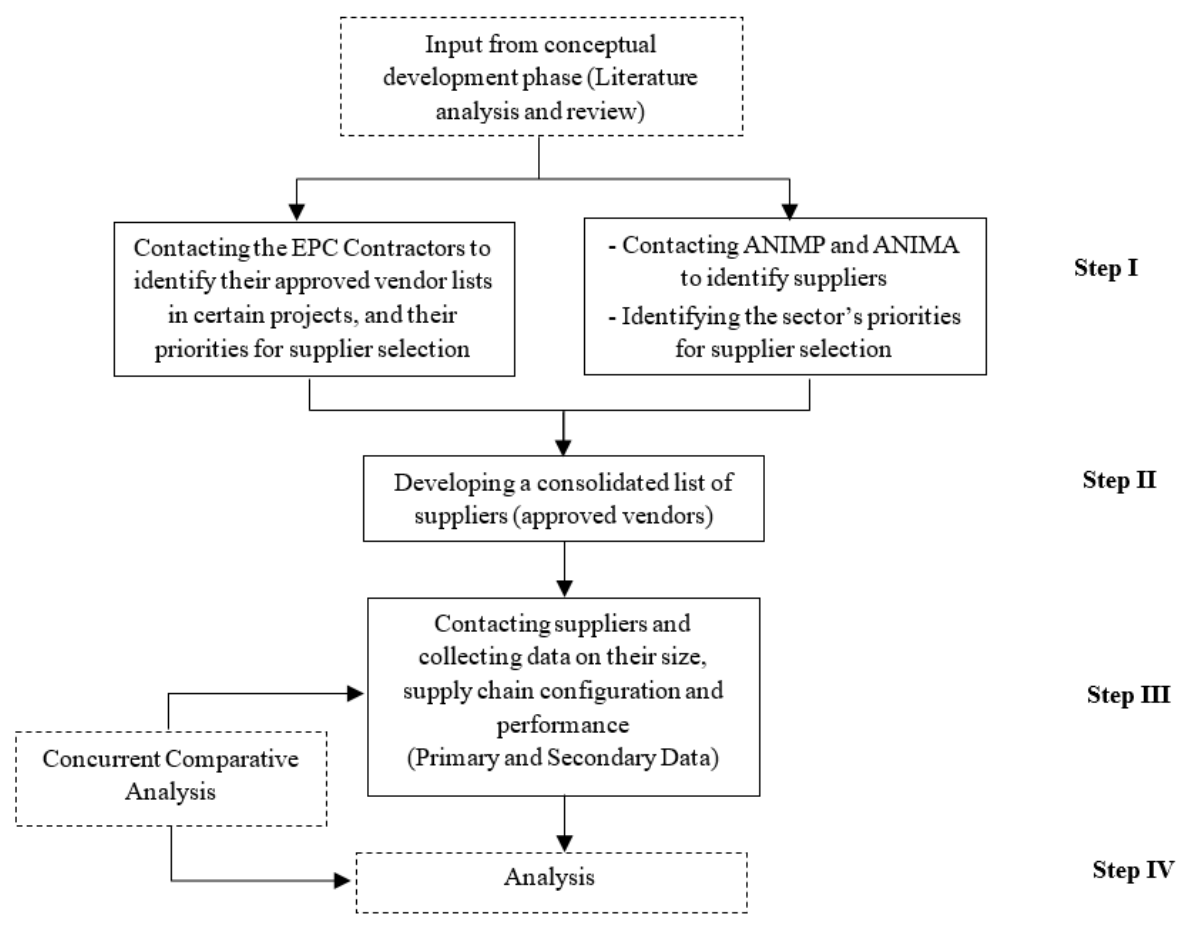

The interview questions for the 20 suppliers were designed in such a way to capture the 9 collaboration and partnering conceptual dimensions outlined above in Table 1. In doing so, the interviews addressed the following topics: 1) longitudinal and historical strategic decisions of the supplier that help improve performance and competitiveness; 2) closeness of the relationships with their raw material suppliers and the EPC contractors; 3) coordination mechanisms, collaboration activities, the duration of the relationships and frequency of relational transactions; 4) product 
specifications and scope of transactions; 5) main performance measures employed in operations and facility capacities; 6) corporate and supply chain strategy. The scope of supply chain configuration in this paper is: i) the localisation/globalisation level of their raw material suppliers; ii) collaboration; and iii) partnerships (Chandra and Grabis, 2007; Sezen, 2008; Chopra and Miendle 2012; Ruuska et al., 2013; Corominas et al., 2015; Behera et al., 2015). Similarly, the interview questions in the six EPC contractors interviews focused on their criteria for supplier selection, supplier development initiatives, and the main criteria for adding suppliers to their firstchoice list (i.e. as a preferred vendor), as well as the longevity and closeness of their relationships with their suppliers, geographical region of interest, and collaboration and information sharing with the suppliers.

\section{Data Analysis Method}

A total of 14 suppliers from the oil and gas valves supply network (1) were coded SV1-SV14. Six suppliers which belonged to the pressure equipment supply network (2) were coded PS15-PS20. This resulted in a final sample of 20 suppliers from the two supply networks.

The aim here is to investigate the salient characteristics of these best-in-class suppliers to identify what helps a supplier get selected by EPC contractors. The data analysis is performed on; the suppliers' supply chain configuration, performance and size.

Having a large number of variables and respondents in our research, we decided to apply classification logic -that is, in addition to thematic analysis- to help us organise the analysis and make sense of the complex data, to provide meaningful insights (Guest and Mclellan, 2003; Macia, 2015). Classification and cluster analysis helped us detect recurring patterns in the suppliers' data which could help identify the most salient elements that enhance a supplier's opportunity in getting approved.

The classification analysis and data preparation are explained below in detail, a simple classification tool was developed for the supplier performance analysis using Bernoulli's distribution through transforming qualitative data to binary data, thematic analysis of qualitative data was used to indicate the suppliers' classification according to supply chain configuration elements, and the suppliers' size classification was performed based on applying the European Commission's definition of SME revised in 2003. 


\section{Suppliers' Performance and Size Analysis}

Here the aim was to develop a classification of suppliers based on a consolidated evaluation of their performance. The central theory of this research is suppliers' performance should be evaluated through a number of qualitative and quantitative criteria, hence we investigated performance through combining both financial and non-financial indicators to establish an accurate account on suppliers' performance. As outlined earlier, we collected supplier performance evaluation data from different sources (recording the suppliers' performance self-evaluation along with the EPC contractors' evaluation of performance indicators in each supplier, secondary data from ANIMP and ANIMA records on supplier evaluation). In doing so, we developed a structured database of the entirety of performance indicators that suppliers' need to satisfy.

To determine which of these indicators are considered performance priorities and essential to get approved by buyers, we developed a rating system through consolidating and transforming qualitative performance data (e.g., important/not important) into binary data, where values of either 1 or 0 are used to represent the importance or lack thereof of each performance indicator to indicate its priority. As a result, a detailed mapping of supplier's performance priorities was developed to help identify their points of excellence. This, combined with the size analysis explained below, has resulted in creating the supplier bands classification (tables 2 and 3).

As explained below in Equation 1, the priority of each performance indicator $\left(x_{\mathrm{i}}\right)$ was calculated as the weighted mean $\left(\bar{W}_{i j}\right)$ using arithmetic mean $\left(\overline{\mathrm{I}}_{\mathrm{i}}\right)$ in discrete probability distribution (Bernoulli's distribution). The weighted mean $\left(\bar{W}_{i j}\right)$ approach reflects the practice that not every performance indicator has the same priority in the supplier selection process.

$$
\begin{aligned}
& \bar{W}_{i j}=\frac{\sum_{\mathrm{i}=1}^{\mathrm{n}} \overline{\mathrm{I}}_{\mathrm{ij}} \cdot x_{i}}{\sum_{\mathrm{i}=1}^{\mathrm{n}} \overline{\mathrm{I}}_{\mathrm{ij}}} \\
& \text { s.t. } \quad x_{i} \in\{\mathbf{0}, \mathbf{1}\}, \quad x_{i}= \begin{cases}\mathbf{1} & \text { Important } \\
\text { where } & \text { Otherwise }\end{cases}
\end{aligned}
$$

$\bar{W}_{i j} \quad$ Weighted mean of performance indicator $i$ in supplier $j$

$\overline{\mathrm{I}}_{\mathrm{i}} \quad$ Arithmetic mean of performance indicator $i$ in supplier $j$

$x_{\mathrm{i}} \quad$ Consolidated evaluation of the importance of performance indicator $i$ 
We performed the band classification of each supplier in two steps. Firstly, we calculated the values of the weighted mean $\left(\bar{W}_{i j}\right)$ of performance indicators in each supplier, assigning letter $A$ to the suppliers which scored values higher than $80 \%$. Letter $B$ indicated values between $40 \%$ and $80 \%$, and letter $C$ stood for values lower than $40 \%$.

Secondly, to include the financial performance dimension, the size of the suppliers as an indicator of their financial fitness was used. To determine a supplier's size, we applied the European Commission's SME definition (Commission Recommendation 2003/361/EC): “The category of micro, small and medium-sized enterprises (SMEs) is made up of enterprises which employ fewer than 250 persons, and which have an annual turnover not exceeding EUR 50 million, and/or an annual balance sheet total not exceeding EUR 43 million."

Those which had a turnover of 200 million euros or above are indicated as High $(\mathrm{H})$, between 50 and 200 million euros are indicated as medium (M), and those with below 50 million euros are indicated as Low (L). As a result, a classification of nine supplier bands (AH, AM, AL, BH, BM, $\mathrm{BL}, \mathrm{CH}, \mathrm{CM}, \mathrm{CL}$ ) was developed based on the consolidation of the values of the weighted mean scores $\left(\bar{W}_{i j}\right)$ of their key performance priorities and financial size/fitness (High, Medium and Low).

Table 2. Suppliers' Bands System

\begin{tabular}{|c|c|c|c|c|}
\hline \multicolumn{2}{|c|}{$\begin{array}{c}\qquad \overline{\boldsymbol{W}}_{\boldsymbol{i j}} \\
\text { weighted importance of } \\
\text { performance indicators } \\
(A, B, C)\end{array}$} & \multicolumn{2}{|c|}{$\begin{array}{c}\text { Size } \\
\text { (Million Euros) } \\
(H, M, L)\end{array}$} & $\begin{array}{c}\text { Supplier } \\
\text { Band } \\
\text { Classification }\end{array}$ \\
\hline$>80 \%$ & $A$ & $\begin{aligned} & \geq 200 \\
> & 50<200 \\
& \leq 50\end{aligned}$ & $\begin{array}{c}H \\
M \\
L\end{array}$ & $\begin{array}{l}\mathbf{A H} \\
\mathbf{A M} \\
\mathbf{A L}\end{array}$ \\
\hline$\geq 40 \% \leq 80 \%$ & $\boldsymbol{B}$ & $\begin{aligned} & \geq 200 \\
> & 50<200 \\
& \leq 50\end{aligned}$ & $\begin{array}{c}H \\
M \\
L\end{array}$ & $\begin{array}{c}\text { BH } \\
\text { BM } \\
\text { BL }\end{array}$ \\
\hline$<40 \%$ & $C$ & $\begin{aligned} & \geq 200 \\
> & 50<200 \\
& \leq 50\end{aligned}$ & $\begin{array}{c}H \\
M \\
L\end{array}$ & $\begin{array}{l}\mathrm{CH} \\
\mathrm{CM} \\
\mathrm{CL}\end{array}$ \\
\hline
\end{tabular}

Table 3. Supplier Bands Legend

\begin{tabular}{|c|c|c|c|}
\hline \multirow{5}{*}{ 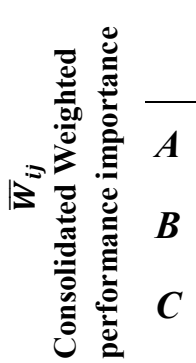 } & \multicolumn{3}{|c|}{ Supplier Size } \\
\hline & High & Medium & Low \\
\hline & $\mathbf{A H}$ & $\mathbf{A M}$ & $\mathbf{A L}$ \\
\hline & BH & BM & BL \\
\hline & $\mathbf{C H}$ & $\mathbf{C M}$ & CL \\
\hline
\end{tabular}

As shown below in table 4, through applying these criteria, it was determined that the majority of the suppliers (14) were larger enterprises, whilst 6 could be considered SME. 
Table 4. Initial Supplier Classification

\begin{tabular}{|c|c|c|c|c|c|c|}
\hline Supplier & $\begin{array}{c}\text { Supply } \\
\text { Network }\end{array}$ & $\begin{array}{c}\text { No. } \\
\text { Employees }\end{array}$ & $\begin{array}{c}\text { Size } \\
\text { Turnover } \\
\text { (MEuro) }\end{array}$ & SME Supplier? & $\bar{W}_{i j}$ & $\begin{array}{c}\text { Supplier } \\
\text { Band }\end{array}$ \\
\hline$S V 1$ & 1 & $<100$ & 200 & No & 0.36 & $\mathrm{CH}$ \\
\hline$S V 2$ & 1 & $100-1000$ & 200 & No & 0.67 & $\mathrm{BH}$ \\
\hline SV3 & 1 & $100-1000$ & 50 & SME & 1.00 & $\mathrm{AL}$ \\
\hline$S V 4$ & 1 & $<100$ & 50 & SME & 1.00 & $\mathrm{AL}$ \\
\hline$S V 5$ & 1 & $100-1000$ & $50-200$ & No & 0.33 & $\mathrm{CM}$ \\
\hline$S V 6$ & 1 & $100-1000$ & $50-200$ & No & 0.69 & BM \\
\hline$S V 7$ & 1 & $100-1000$ & $50-200$ & No & 1.00 & $\mathrm{AM}$ \\
\hline$S V 8$ & 1 & $100-1000$ & $50-200$ & No & 0.31 & $\mathrm{CM}$ \\
\hline$S V 9$ & 1 & $100-1000$ & $50-200$ & No & 1.00 & $\mathrm{AM}$ \\
\hline SV10 & 1 & $<100$ & 50 & SME & 0.36 & $\mathrm{CL}$ \\
\hline SV11 & 1 & $<100$ & 50 & SME & 1.00 & $\mathrm{AL}$ \\
\hline SV12 & 1 & $100-1000$ & $50-200$ & No & 1.00 & $\mathrm{AM}$ \\
\hline SV13 & 1 & $100-1000$ & 50 & SME & 0.64 & $\mathrm{BL}$ \\
\hline SV14 & 1 & $100-1000$ & 200 & No & 1.00 & $\mathrm{AH}$ \\
\hline PS15 & 2 & $100-1000$ & 50 & SME & 0.69 & $\mathrm{BL}$ \\
\hline PS16 & 2 & $100-1000$ & $50-200$ & No & 1.00 & $\mathrm{AM}$ \\
\hline PS17 & 2 & nd & $50-200$ & No & 0.64 & $\mathrm{BM}$ \\
\hline PS18 & 2 & nd & $50-200$ & No & 1.00 & $\mathrm{AM}$ \\
\hline PS19 & 2 & nd & $50-200$ & No & 0.36 & $\mathrm{CM}$ \\
\hline PS20 & 2 & $100-1000$ & $50-200$ & No & 1.00 & $\mathrm{AM}$ \\
\hline
\end{tabular}

\section{The Analysis Approach of Supply Chain Configuration}

In this analysis, we applied the definitions of supply chain inter-organisational relationships types put forth by Lambert et al. (1996) and complemented it with the number of transactions, longevity and closeness dimensions from Goffin et al. (2006), as shown in figure 3.

Arm's length is weak collaboration where there can be multiple transactional exchanges yet without joint commitment- in both the short- and long-term. Strong collaboration is where collaborative activities are implemented in the relationship through established coordination mechanisms - in both the short- and long-term, the relationship could be transactional (e.g., the buyer maintains the relationship due to lower prices which enhances cost-efficiency). On the other hand, the partnership continuum deals with closer relationships where integration mechanisms are implemented usually on the long term. Weak partnerships are characterised by the implementation of some integrative mechanisms and functional teams. Strong partnerships are relationships where there is full integration between the supply chain members on the long-term. 
Collaborative relationships can be appropriate with either a large number or few selected supply chain members, yet partnerships are not appropriate to be established with the entire supply base and as such they are usually established with a few selected suppliers.

Figure 3. Projects supply chain inter-organisational relationships.

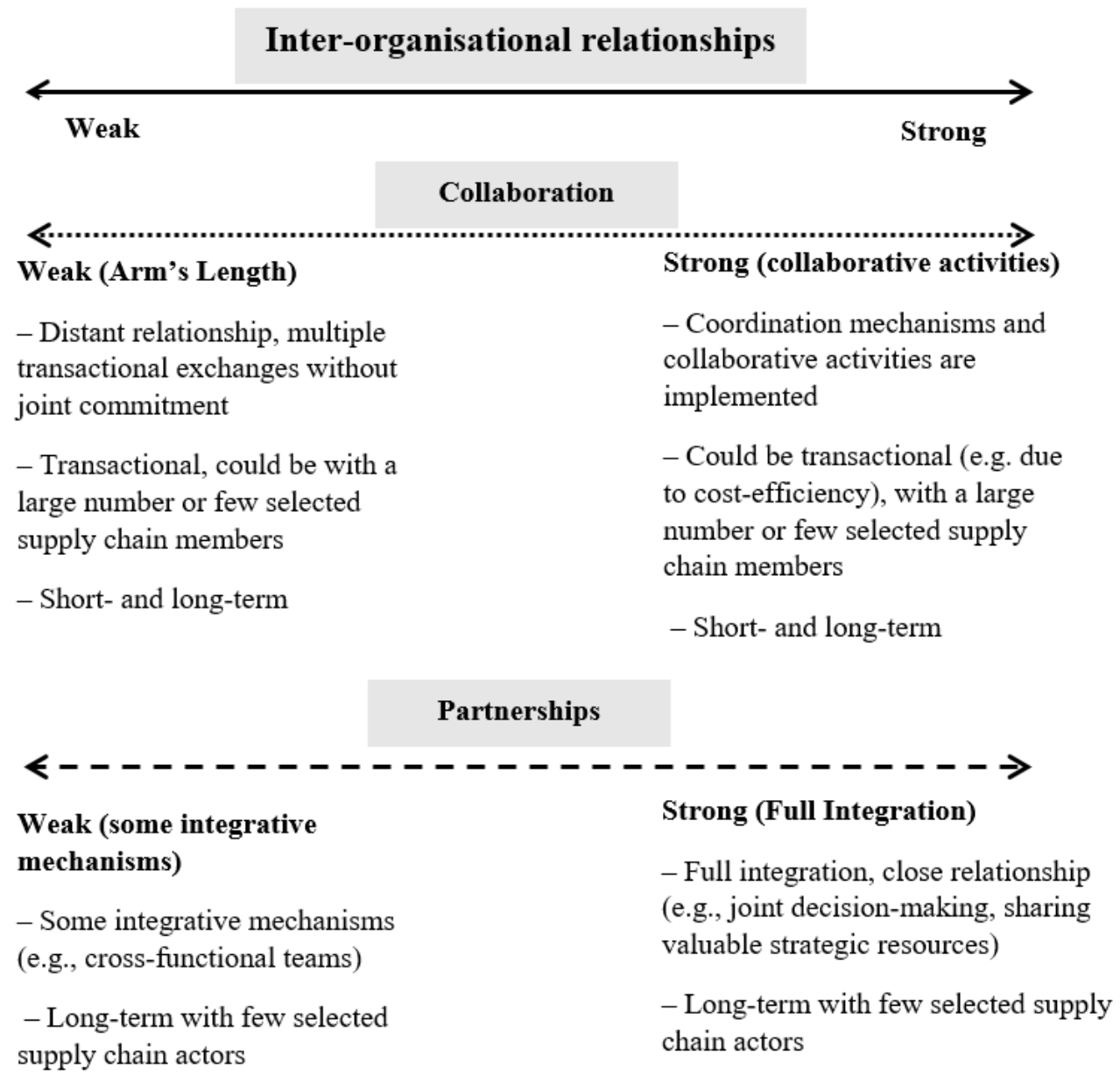

\section{Research Quality}

Case-based research is often criticised for lacking rigour, validity, and transparency in framing protocol (Gibbert et al., 2008; Barratt et al., 2011; Ketokivi and Choi, 2014). In the present study, we embrace the insights of Yin (2018) and Gibbert and Ruigrok (2010) on establishing rigour and validity in case-based research by ensuring construct validity through synthesising the literature review on supply chain configuration from a systems perspective, and developing nine dimensions (Table 1) to guide conceptualising supply chain collaboration and partnerships in the projects environment. Size determination was performed based on the European Commission 
recommendation, which resulted in a consistent classification of the supplier sample. Data collection was performed in line with the conceptualisation carried out in the conceptual development phase (Table 1) and data triangulation was ensured by collecting data from multiple sources, such as interviews, company documents, and ANIMP and ANIMA reports. The supplier classification bands based on a consolidated evaluation of the weighted importance of performance indicators and the supplier's size, resulting in a robust classification system (Tables 2 and 3). Rigour of data analysis was also ensured through triangulation of researchers, audio recording and transcribing of interviews; afterwards, transcripts were sent to the respondents for confirmation.

\section{Findings}

\section{Supplier Selection in the EPC projects environment}

The supplier selection process starts with a supplier's application to be selected as an 'end-user vendor'. Suppliers are required to provide various company details, as depicted in Table 5, such as annual financial turnover, list of assets, fluidity and cash flow, bank references, as well as health, safety, environmental, and quality certifications, where financial capacity is considered a gatekeeper. Suppliers are certified based on their products, and so supplier certification does not cover the entire range of a supplier's products, but only the required items. For the sake of quality assurance, a product expert (from the EPC contractor) periodically visits the supplier facilities to check the manufacturing process and to audit the quality procedures. Supplier certification needs to be renewed every two years, after which their performance is re-evaluated.

Table 5. Preliminary information needed by EPC contractors for supplier qualification

\begin{tabular}{|c|c|}
\hline Fiscal & Parent companies, annual turnover, list of assets, fluidity and cash flow, bank references \\
\hline Commercial & Past experiences with contractors, referees list \\
\hline Operational & $\begin{array}{l}\text { Company details, procurement data, e-commerce activities, operational and information } \\
\text { technology capabilities }\end{array}$ \\
\hline Organisational & Organisational structure, number of employees, management style \\
\hline Certification & Patents and licences, health safety and environment, Quality Management Systems \\
\hline
\end{tabular}

The findings from the suppliers' interviews on the used performance indicators reveal that good knowledge and awareness of performance was achieved. Seven performance indicators emerged from the responses: quality, cost-efficiency, service level, flexibility, technology investment, differentiation, utilisation (equipment and machinery), and personnel training and human resources management. Figure 4 depicts the frequencies (i.e. the number of suppliers which 
employed these performance indicators). A notable prevalence of product quality measures, a priority for 16 out of the 20 suppliers, reflects the importance of product quality as the main indicator of supplier selection in the EPC projects supply chain. Cost-efficiency and high levels of service to the end customer come next after quality; indeed, these were considered as a priority by 15 and 14 of the 20 suppliers, respectively. These two factors are also considered of the utmost importance when it comes to suppliers surviving in today's competitive markets. Flexibility, equipment and machinery utilisation, and investment in technological development are relatively less important than the first three performance measures, being considered a priority by 9 out of the 20 suppliers. Only 7 of the 20 suppliers considered personnel training and human resource development to be a priority. EPC contractors apparently have three main performance priorities in the supplier selection process after passing a financial assessment, namely: level of product quality, cost-efficiency and service level. Of those performance priorities, a supplier should fully satisfy at least one priority (i.e., excellence evaluation) to be approved. Given this, all the remaining priorities should be satisfactorily developed by the suppliers.

Figure 4. Frequency of performance priorities among the supplier sample

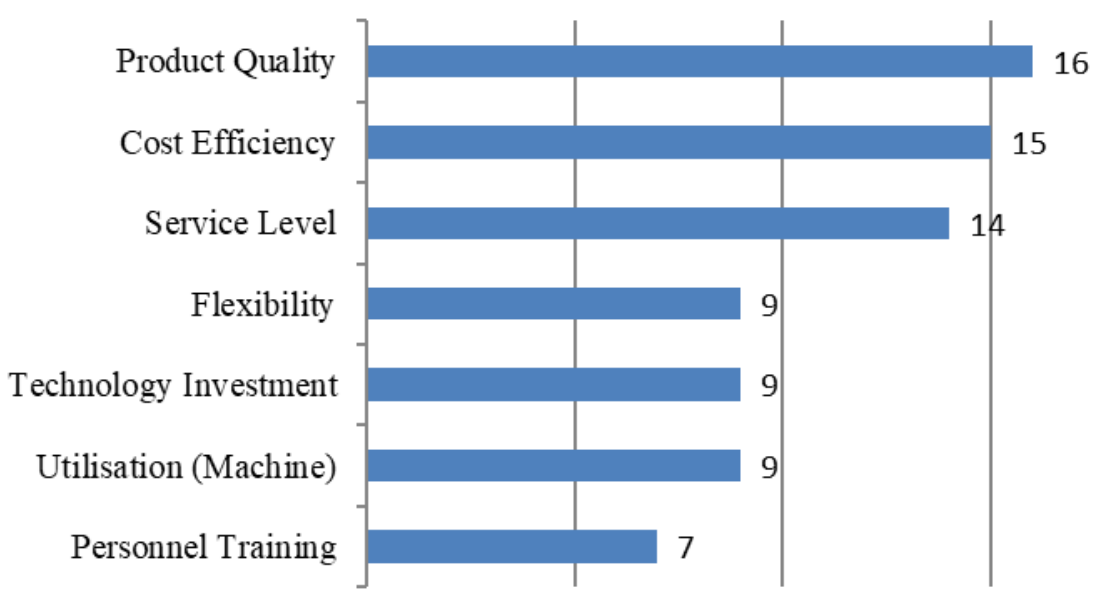

The value of the Mean for each performance indicator was calculated. According to Bernoulli's distribution, the Mean equals the probability weighted sum of the corresponding values. That has resulted in 0.8 Mean value for quality (that means there is $80 \%$ probability that the approved supplier will have quality as a performance priority). For cost efficiency, the calculated Mean value is 0.75 , Service level is 0.7 , flexibility, technology investment and machine utilisation has Mean value of 0.45 while personnel training has Mean value of 0.35 . In developing the suppliers' 
classification (see Tables 2 and 3), we considered the top performance indicators with the highest probability value- that are; quality, cost-efficiency and service level.

\section{Level of Localisation/Globalisation of supply networks}

Many suppliers choose to forge strategic long-term agreements with their raw material suppliers. Strategies of supply localisation are employed to obtain the highest quality possible through contracting raw material from Italy and Europe. The analysis also demonstrates that great attention is paid to global expansion to new markets and to exploring geographical regions that were not among the traditional markets of the European suppliers, which might entail greater supply risks as well as challenges in the form of cultural and language barriers. There is also a great emphasis on investment in research and development activities. Moreover, a considerable buyer and customer involvement in the supplier operations is prevalent, presumably because the bargaining power remains in the downstream in the supply chains in the EPC projects environment.

Procurement of raw materials is performed by selecting best-in-class suppliers, with a notable tendency towards reshoring and localisation to Europe to ensure quality. Certain firms outsource some of their semi-finished components, yet with strict quality assurance procedures. Raw material suppliers are evaluated periodically based on their products, as one manager elaborated: "Suppliers are considered part of the firm. Trust, mutual aid, improvement, and reliability build the competitiveness of the firm"; the manager also stated that "nearby plants, local suppliers, and slack capacity allows the firm to modify production plans in an agile way".

\section{Collaboration and Partnerships}

The studied suppliers seek to establish collaborative strategies in both their upstream (with raw material suppliers) and downstream (with EPC contractors and project owners) supply chains. Considering the characteristics of the supply chains in the EPC projects, fostering stronger and closer customer relationships and project owner involvement is essential in order to survive the competition, as one manager stated: "The continuous exchange of information and data between the firm and its customers creates high-quality customer service". Inter-organisational relationships usually extend beyond information sharing on stocks to focus on new product development and process improvement. Partnership and collaborative strategies are implemented not only between suppliers and EPC contractors, but also with investors and banks. This emphasises the attention which the suppliers pay to supply chain finance solutions, as illustrated 
in one response: "To create something unique for clients, the firm builds very good relationships with customers, but also with banks and financiers".

In summary, the suppliers focus on "an advanced supplier selection system, an efficient cost breakdown structure, and an accurate analysis of risks, allowing the firm to carefully manage projects".

\section{Discussion}

A crosschecking of the EPC contractors' responses with those of the suppliers, combined with the information collected earlier from ANIMP and ANIMA, has resulted in the validation of three measures as the main performance priorities in the EPC sector: quality, cost-efficiency and service level. Moreover, we were able to robustly assess which performance priorities were fully satisfied by which supplier (i.e. approved-level), and to classify suppliers based on a combination of the values of the weighted Mean scores of their key performance priorities and financial size (see Tables 2 and 3). The supplier bands system is applied where the performance of each supplier is a combination of its size and the weighted mean of performance priorities (see Tables 2, 3 and 4). The SME are represented by rhombuses and the non-SME are represented by circles (see Figure 5). Here we examine the suppliers' supply chain configuration while capturing the size and the performance level of each supplier (see Figures 6 and 7), depicting the ranges of each variable. Level of localisation/globalisation ranges from locally concentrated in Europe to globally extended worldwide.

Figure 5. SME Legend

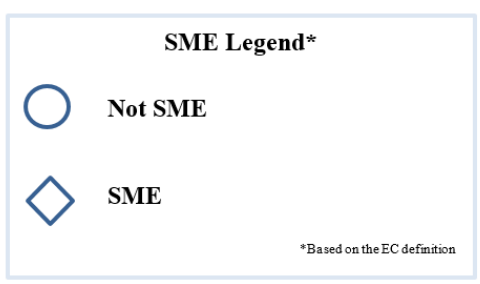

\section{Collaboration, level of Localisation/Globalisation}

This relationship is depicted in Figure 6. The analysis presented here draws heavily on the collaboration conceptualisation presented in Table 1 and Figure 3. Many suppliers are geared towards globalising supply and establishing close collaboration in the upstream and downstream 
supply chains. Another subgroup of the suppliers (i.e. SV4, SV6, SV8, SV12 and SV1) have close collaboration but within a locally concentrated supply.

The analysis reveals that although the majority of the supply chains are partially-to-fully extended globally, reshoring strategies are underway, and 8 of the 20 suppliers are localising their supply in Italy (i.e. SV4 - 8, SV10, SV12 and SV1). Their focus on local supply is to offer highquality customised products might explain how such firms survive without expanding globally.

The majority of the suppliers which opt for implementing coordination mechanisms and collaborative activities in both the short- and long-term have a medium to high-performance score (i.e. blue and yellow colour), yet with different globalisation/location settings. The analysis reveals that most globally extended suppliers implement coordination mechanisms and collaborative activities, suggesting that close collaboration is essential when it comes to surviving the potential risks of global expansion. This is because such close collaboration can be an enabler for the suppliers to offer higher service level, quality, and better their cost-efficiency.

Figure 6. Collaboration and level of localisation / globalisation

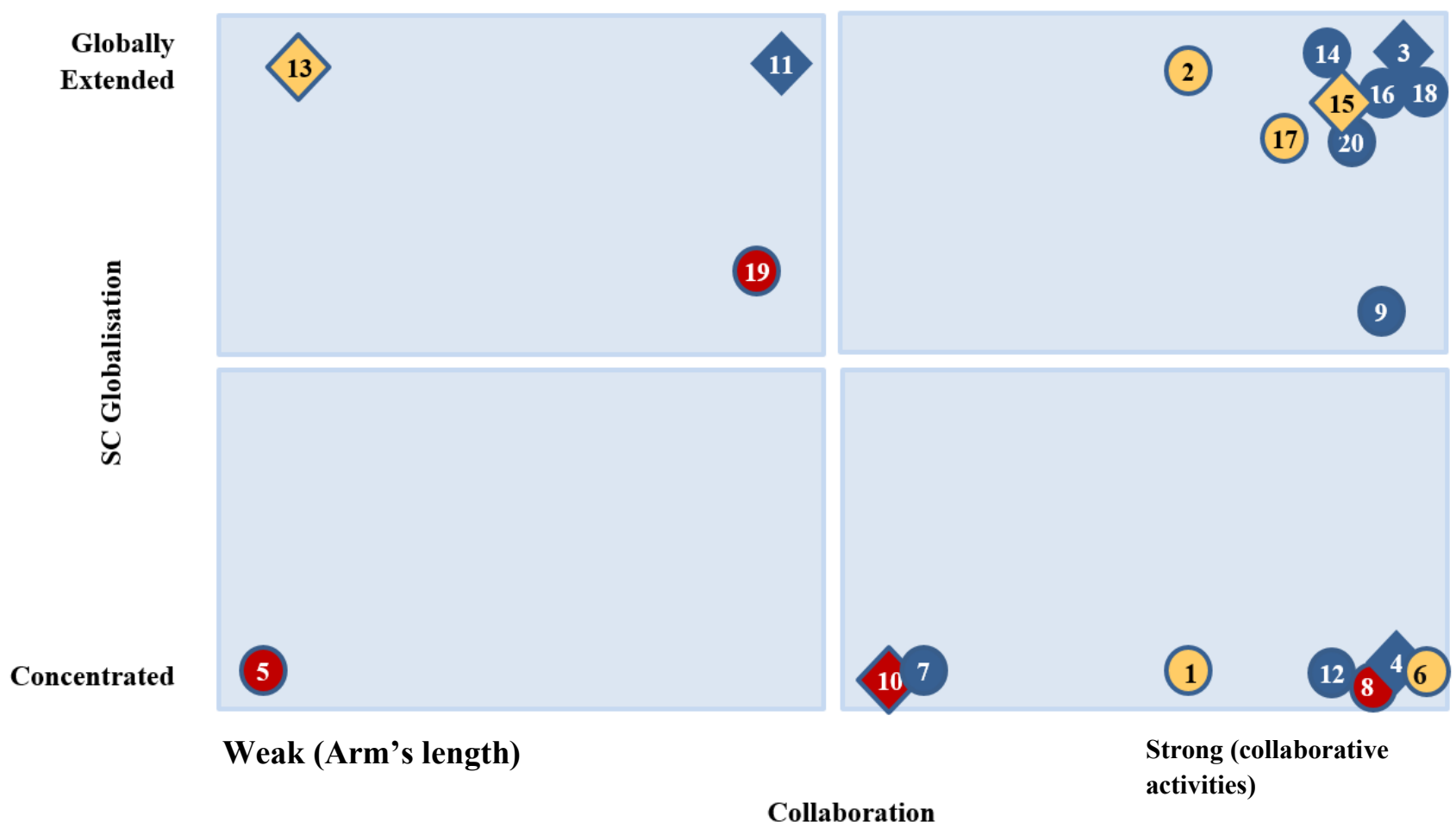




\section{Partnering, level of Localisation/Globalisation}

This relationship is depicted in Figure 7. The analysis presented here draws on the partnership conceptualisation presented in Table 1 and Figure 3.Two significant subgroups can be identified. The first comprises suppliers implementing some integrative mechanisms (weak partnership), but to be able to improve their cost efficiency, they extend their supply globally to survive the competition, as in SV9, SV13, SV14, and PS15-20. The second subgroup comprises the suppliers with partial to strong partnerships but locally concentrated supply as in SV1, SV4-8 and SV10. The figure shows that when a supply chain is locally concentrated, suppliers tend to be fully integrated. By doing this, suppliers can utilise the resources of other supply chain members, eventually building the necessary capabilities to survive market competition, while the supply localisation in Europe enables them to offer high-quality products at a reasonable cost.

Figure 7. Partnerships and level of localisation / globalisation

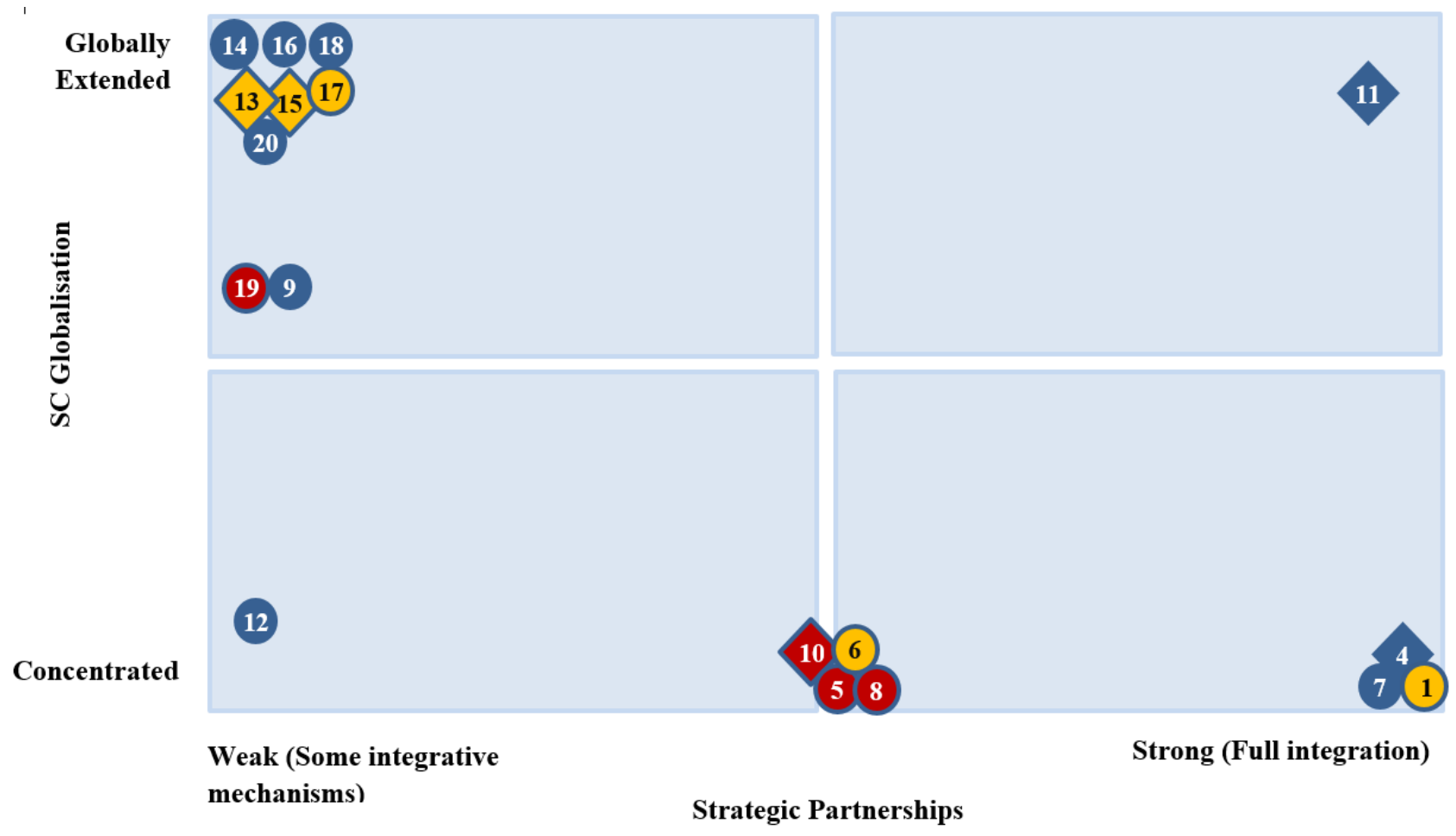

\section{Supplier Size and Performance}

As can be seen in Figure 6, the majority of SME (SV3, SV11, SV13, and PS15) opt for globalising their supply network, with an inclination towards implementing coordination mechanisms and 
collaborative activities, as in SV10, SV4, PS15 and SV3. Only two SME suppliers have an arm's length relationship with their supply network (SV13 and SV11).

Most of the SME represented in figure 7 (e.g. SV13, PS15 and SV10) implement some integrative mechanisms but shy away from full integration. This analysis suggests that when a supply chain is globally extended, it can be costly to small suppliers to implement full integration, as this might limit suppliers flexibility and control over their resources, especially with small and medium-sized enterprises.

This cluster analysis has revealed suppliers SV5, SV11, SPV12 and SV13 as interesting cases and candidates for future research. SV11 is an SME supplier but has a globally extended supply; however, fostering strong partnerships and full integration might explain how SV11 is in the highperformance band. In contrast, suppliers SV5 and SV12 are non-SME, which might have enabled them to focus on selected performance priorities while their supply is localised in Italy (i.e. expensive purchasing of raw material), as well as weak integration/collaboration. This suggests that SPV5 and SPV12 focus on offering high-quality niche products.

SV13 is an SME supplier in the BL medium performance band; it has an arm's length relationship with its suppliers and implements a few integrative mechanisms while being globally extended. Though SV13 is deemed, based on assessment, to be an average-to-high performer, the research team believes that the combination of its size and supply chain configuration suggests it might not survive the global competition for a long period among high performers. After a few months of this analysis, SV13 went out of business and was acquired by a large Japanese group.

\section{Supply Chain Configuration Map}

In light of the above discussion, four zones emerge from the analysis as potential zones where suppliers in the projects environment can position their supply chains: Zones A, B, C and D. We combine collaboration and partnerships in inter-organisational relationships dimension, as explained in figure 8 , to produce a consolidated supply chain configuration framework that helps suppliers leverage on their points of excellence to get selected.

Zone $A$ is suitable for suppliers that have innovation capability, which helps them offer niche products. The supply chain configuration is localised to offer high-quality raw material, with arm's length relationships and weak upstream supply chain integration, hence lowering uncertainty and risks. Managing this supply chain requires basic configuration and risk assessment capabilities. 
Zone $B$ can be an ideal position for small suppliers, as here they use the relational resources generated from strong collaboration and full integration, which enables them to offer higher quality and service levels at reasonable costs. In Zone $B$ the supply chain configuration is localised to enable suppliers to focus on high quality and service level strategy. There is close collaboration and full upstream supply chain integration, which, along with the localisation, helps decrease uncertainty and risks, hence managing this supply chain requires moderate configuration and risk assessment capabilities.

Zone $C$ can be an ideal position for larger suppliers, with its cost-efficient supply chain strategy and global supply chain configuration. Similar to Zone $B$, in Zone $C$ suppliers use valuable relational resources resulting from the close collaboration and full upstream supply chain integration. As a result of the global expansion, high uncertainty and risks are expected. Managing this supply chain requires enhanced supply chain configuration and risk assessment capabilities to manage a network of global inter-organisational relationships.

Zone $D$ can be suited to larger suppliers, yet might be a risky position for smaller ones. The supply chain configuration is globalised due to a focus on cost-efficiency. The relationships are arm's length relationships, and there is weak upstream supply chain integration, hence high uncertainty and risks may exist. Managing the supply chain from this position requires enhanced supply chain configuration, risk assessment capabilities and better resource management due to the expected lack of relational resources. 
Figure 8. A Framework for supply chain configuration

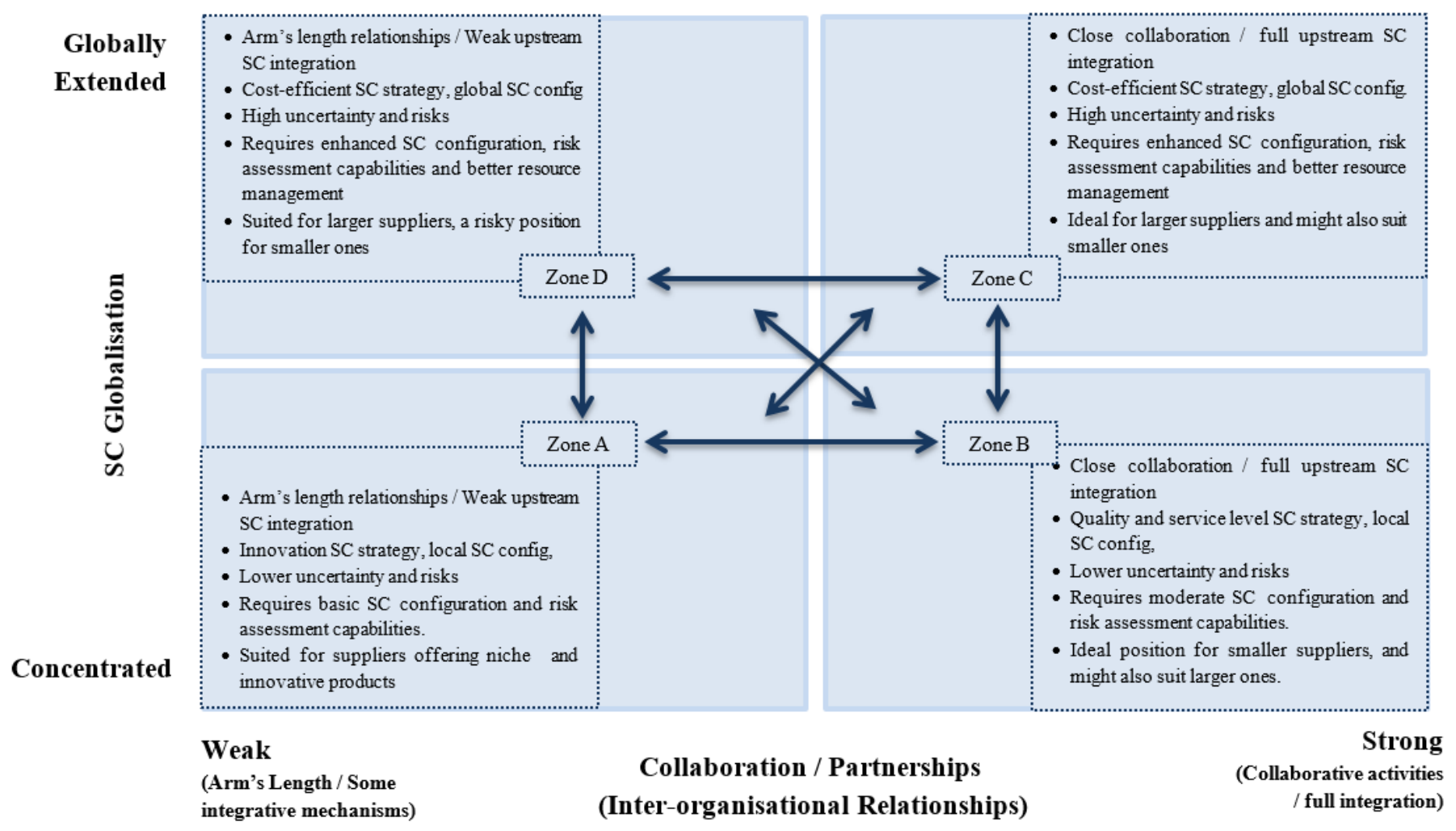

Suppliers can change their product's supply chain configurations and strategy, and hence change the supply chain's position (i.e. Zone), yet the implications of such movements need to be taken into consideration. We put forward a supply chain configuration positioning framework which explains in detail the considerations to be implemented when changing the configuration strategy in projects environment (i.e. moving move from one zone to another), as shown in Table 5.

Zone $A$ is best suited for suppliers offering niche products; those suppliers moving to Zone $A$ may need to improve their innovation capability, which will enable them to offer innovative products, yet they are likely to lose the relational resources they have built if they are moving from Zone $B$ or $C$; it is also likely that the supply chain costs will increase, especially if moving to Zone $A$ from $D$ or $C$ (since they offer cost-efficient products); therefore, suppliers may need to focus on enhancing their resource management capability.

Those suppliers moving to Zone $B$ from $A$ or $D$ need to improve their supply chain configuration and resource management capabilities to be able to manage the network of inter-organisational relationships. Moreover, those moving from Zone $C$ need to improve their quality management 
capability. Moving to Zone B may enable suppliers to offer higher quality and service level, and to foster stronger supply chain relationships. However, it may incur increased complexity when it comes to managing these relationships, as well as increased costs due to the localisation of raw material in Zone B.

Moving to Zone $C$ or $D$ can save costs and offers expansion to new markets, although the supply chain vulnerability may increase due to global expansion; this is in addition to the expected language and cultural barriers, especially in Zone $C$. Therefore, suppliers moving to Zone $C$ or $D$ need to improve their supply chain configuration and risk assessment capabilities. Furthermore, moving to Zone D may lead to a potential loss of relational resources, and hence suppliers need to enhance their resource management capability.

Table 5. A Framework for supply chain configuration positioning

\begin{tabular}{|c|c|c|c|c|c|}
\hline From & To & Direction & $\begin{array}{l}\text { Considerations to } \\
\text { be implemented }\end{array}$ & Advantages & Disadvantages \\
\hline Zone A & Zone B & & $\begin{array}{l}\text { Improve supply } \\
\text { chain configuration } \\
\text { and resource } \\
\text { management } \\
\text { capabilities. }\end{array}$ & $\begin{array}{l}\text { Offering higher } \\
\text { service levels, } \\
\text { Fostering stronger } \\
\text { SC relationships. }\end{array}$ & $\begin{array}{l}\text { Increased supply chain } \\
\text { complexity due to } \\
\text { establishing network of } \\
\text { relationships. }\end{array}$ \\
\hline Zone A & Zone D & & $\begin{array}{l}\text { Improve supply } \\
\text { chain configuration } \\
\text { and risk assessment } \\
\text { capabilities. }\end{array}$ & $\begin{array}{l}\text { Cost efficiency, } \\
\text { expansion to new } \\
\text { markets. }\end{array}$ & $\begin{array}{l}\text { Increased supply chain } \\
\text { vulnerability due to } \\
\text { global expansion, } \\
\text { language and cultural } \\
\text { barriers. }\end{array}$ \\
\hline Zone A & Zone C & & $\begin{array}{l}\text { Improve supply } \\
\text { chain configuration, } \\
\text { risk assessment and } \\
\text { resource } \\
\text { management } \\
\text { capabilities. }\end{array}$ & $\begin{array}{l}\text { Cost efficiency, } \\
\text { expansion to new } \\
\text { markets. }\end{array}$ & $\begin{array}{l}\text { Increased supply chain } \\
\text { vulnerability due to } \\
\text { global expansion. }\end{array}$ \\
\hline Zone B & Zone A & & $\begin{array}{l}\text { Improve innovation } \\
\text { capability. }\end{array}$ & $\begin{array}{l}\text { Offering innovative } \\
\text { products. }\end{array}$ & $\begin{array}{l}\text { Potential loss of } \\
\text { relational resources. }\end{array}$ \\
\hline Zone B & Zone C & $\uparrow$ & $\begin{array}{l}\text { Improve supply } \\
\text { chain configuration } \\
\text { and risk assessment } \\
\text { capabilities. }\end{array}$ & $\begin{array}{l}\text { Cost efficiency, } \\
\text { expansion to new } \\
\text { markets. }\end{array}$ & $\begin{array}{l}\text { Increased supply chain } \\
\text { vulnerability due to } \\
\text { global expansion, }\end{array}$ \\
\hline
\end{tabular}




\begin{tabular}{|c|c|c|c|c|c|}
\hline & & & & & $\begin{array}{l}\text { language and cultural } \\
\text { barriers }\end{array}$ \\
\hline Zone B & Zone D & $\nabla$ & $\begin{array}{l}\text { Improve supply } \\
\text { chain configuration } \\
\text { and risk assessment } \\
\text { capabilities. }\end{array}$ & $\begin{array}{l}\text { Cost efficiency, } \\
\text { expansion to new } \\
\text { markets. }\end{array}$ & $\begin{array}{l}\text { Increased supply chain } \\
\text { vulnerability due to } \\
\text { global expansion, } \\
\text { Potential loss of } \\
\text { relational resources. }\end{array}$ \\
\hline Zone C & Zone B & $\vee$ & $\begin{array}{l}\text { Improve quality } \\
\text { management } \\
\text { capability. }\end{array}$ & $\begin{array}{l}\text { Offering higher } \\
\text { quality and service } \\
\text { levels. }\end{array}$ & $\begin{array}{l}\text { Increased supply chain } \\
\text { costs. }\end{array}$ \\
\hline Zone C & Zone D & $<$ & $\begin{array}{l}\text { Improve resource } \\
\text { management } \\
\text { capability. }\end{array}$ & Cost efficiency. & $\begin{array}{l}\text { Potential loss of } \\
\text { relational resources. }\end{array}$ \\
\hline Zone C & Zone A & & $\begin{array}{l}\text { Improve innovation } \\
\text { and resource } \\
\text { management } \\
\text { capabilities. }\end{array}$ & $\begin{array}{l}\text { Offering innovative } \\
\text { products. }\end{array}$ & $\begin{array}{l}\text { Increased supply chain } \\
\text { costs, } \\
\text { Potential loss of } \\
\text { relational resources. }\end{array}$ \\
\hline Zone D & Zone C & $\longrightarrow$ & $\begin{array}{l}\text { Improve supply } \\
\text { chain configuration } \\
\text { and resource } \\
\text { management } \\
\text { capabilities. }\end{array}$ & Cost efficiency. & $\begin{array}{l}\text { Increased supply chain } \\
\text { complexity due to } \\
\text { establishing network of } \\
\text { relationships. }\end{array}$ \\
\hline Zone D & Zone A & $\vee$ & $\begin{array}{l}\text { Improve innovation } \\
\text { and resource } \\
\text { management } \\
\text { capabilities. }\end{array}$ & $\begin{array}{l}\text { Offering innovative } \\
\text { products. }\end{array}$ & $\begin{array}{l}\text { Increased supply chain } \\
\text { costs. }\end{array}$ \\
\hline Zone D & Zone B & $\Delta$ & $\begin{array}{l}\text { Improve quality } \\
\text { management and } \\
\text { resource } \\
\text { management } \\
\text { capabilities. }\end{array}$ & $\begin{array}{l}\text { Offering higher } \\
\text { quality and service } \\
\text { levels, } \\
\text { Fostering stronger } \\
\text { SC relationships. }\end{array}$ & $\begin{array}{l}\text { Increased supply chain } \\
\text { costs, } \\
\text { Increased supply chain } \\
\text { complexity due to } \\
\text { establishing network of } \\
\text { relationships. }\end{array}$ \\
\hline
\end{tabular}

\section{Conclusion}

This research has argued that supplier selection should incorporate a broad range of financial and non-financial performance indicators to enable establishing a realistic account of suppliers' overall performance in projects environment. The results have supported the inclusion of supply chain configuration, as a capability, in the supplier selection criteria. The research reveals that in 
the supply market of the projects envrionment, best performers are often confused with "best financial" performers. While in many cases, especially when evaluated on the long term, best performers can also be high financial performers, yet it is not always the case on the short term. In fact, we found that some of the suppliers approved by EPC contractors as "best" have modest financial fitness yet with a high combined performance. As such, the capability of partner selection, establishing collaboration and maintaining successful inter-organisational relationships under uncertainty should be reflected in the supplier selection criteria in the projects environment, as it demonstrates that suppliers can develop internal and external knowledge capability (c.f. Ruuska et al., 2013). The research didn't find conclusive evidence to support the claim that a supplier's modest financial fitness lead to lower overall performance levels. Hence, we suggest that size should not condition the supplier selection process in the projects supply chains.

This research makes several contributions to the supply chain literature. Firstly, the majority of previous studies used a project as a unit of analysis. Through considering the supply chain perspective, the present research puts forward a framework detailing four potential zones (i.e. supply chain positions), which led to the provision of the conditions under which suppliers may survive the high-uncertainty environments of the new global market competition settings, in particular through configuring the supply chain, deciding on the needed capabilities, and exploiting the relational resources generated by the implementation of coordination mechanisms and collaborative activities. The research therefore suggests considering supply chain configuration as a capability, the development of which helps buyers to benefit from the generated relational resources and contributes to the improvement of supply networks in the projects environment.

Secondly, through investigating the level of collaboration and degree of partnerships against globalisation, some preliminary results emerged from the analyses, such as; reshoring strategies even with globally-extended supply chains, the implementation of integrative mechanisms to improve cost efficiency, and enhanced full integration when the supply chain is locally concentrated. Thirdly, this paper is one of the first to investigate supplier selection in the projects environment while incorporating the suppliers' self-evaluation and perspective, which has led to the generation of more realistic analyses.

While there is prevalence in implementing collaborative activities and coordination mechanisms between the supply chain members, the analyses reveal there is a lower emphasis on fostering partnerships in the projects supply network. This finding confirms that of Gadde and 
Dubois (2010) that the projects industry norms lean towards exploitation rather than partnering and the findings of Koufteros et al. (2012) which indicats that cost-based supplier selection leads to prevalence of arm's length-type relationships. This finding also supports our decision to study both forms of inter-organisational relationships, and points to a potential opportunistic behaviour from some of the large EPC contractors in investing in full integration and supplier development, which eventually leads to squeezing smaller suppliers. A possible explanation for these results is that projects supply chains are often temporary, hence, fostering strong partnerships and achieving full supplier integration might not always be feasible. Eventually, these practices may turn the supply market to an oligopolistic one with just a few large multinational suppliers; this could have dire consequences, such as harming pure competition and national economies. That is a situation that may harm the business growth of the EPC contractors in the long-term.

The presented analyses offer insights into the EPC projects supply chains - a context rarely addressed in the supply chain configuration literature. Many of the Italian suppliers in the EPC projects environment are pushed by large EPC contractors to globalise their supply chains without proper development of necessary supply chain capabilities, or a governmental scheme to protect the small suppliers from the risks of globalisation. Being of smaller size might have provided these businesses with higher flexibility to address the needs of EPC contractors, yet a rapid global expansion might not allow many of these suppliers to grow and may put their businesses at risk.

This research will help supply chain practitioners, working in the EPC projects environment, during their decision-making on the most suitable supply chain configuration for their businesses. The analysis suggests that there is no one best supply configuration, as this depends on further factors such as the suppliers' capabilities, product portfolios and targeted market.

Future research directions include investigating potential trade-offs between different supplier capabilities and supply chain configuration. Such research can shed light on proper combinations of supply chain configuration and strategy and helps suppliers develop the corresponding capabilities. Moreover, considering the high uncertainty in projects environment, a longitudinal study can prove useful in delineating the dynamics between developing supply chain configuration capability and suppliers' performance levels. We acknowledge the limitations of this research, which mainly concerns the regional concentration and cultural homogeneity of the suppliers in our study, which might entail certain legal requirements or supply management profiles. Though our analysis is in line with earlier studies that point out the difficulty of applying 'normal' supply chain 
conditions in the projects environment (c.f. Hicks et al., 2000; Behera et al., 2015; Gadde and Dubois, 2010), we believe the richness and replication of the present data establish analytical generalisability, offering beneficial transferable insights for practitioners working in other projects environments and industrial sectors. Hence, an important avenue for future research is to investigate the supply chain configuration framework in other projects environment such as construction or shipbuilding supply chains.

\section{References}

Aitken, J., Childerhouse, P., Christopher, M. and Towill, D. 2005. "Designing and managing multiple pipelines." Journal of Business Logistics 26(2):73-96.

Alfalla-Luque, R., Medina-Lopez, C., and Dey, P. K. 2013. "Supply chain integration framework using literature review.” Production Planning \& Control, 24(8-9):800-817.

Aloini, D., Dulmin, R., Mininno, V. and Ponticelli, S., 2015. "Key antecedents and practices for Supply Chain Management adoption in project contexts". International Journal of Project Management, 33(6), pp.1301-1316.

Badorf, F., Wagner, S. M., Hoberg, K., and Papier, F. 2019. "How Supplier Economies of Scale Drive Supplier Selection Decisions.” Journal of Supply Chain Management, 55(3):45-67.

Barratt, M. 2004. "Understanding the meaning of collaboration in the supply chain." Supply Chain Management: an international journal, 9(1):30-42.

Behera, P., Mohanty, R. P., and Prakash, A. 2015. "Understanding construction supply chain management." Production Planning \& Control, 26(16):1332-1350.

Bhatnagar, R. and Sohal, A.S. 2005. "Supply chain competitiveness: measuring the impact of location factors, uncertainty and manufacturing practices." Technovation, 25(5):443-456.

Brancaleoni M., 2015. Follow the global market flow, Industrial Valve Summit May 27-28, 2015.

CII 1990 - 2019. Construction Industry Institute, best practices on partnerships, https://www.construction-institute.org/resources/knowledgebase/best-practices. [Accessed $30^{\text {th }}$ September 2019].

Chan, F. T., and Prakash, A., 2012. "Inventory management in a lateral collaborative manufacturing supply chain: a simulation study." International Journal of Production Research, 50(16):4670-4685.

Chandra, C. and Grabis, J. 2007. "Supply Chain Configuration - Concepts, Solutions, and Applications." Springer, New York. 
Chen, W., Lei, L., Wang, Z., Teng, M., and Liu, J. 2018. "Coordinating supplier selection and project scheduling in resource-constrained construction supply chains." International Journal of Production Research, 56(25):1-15.

Choi, T. Y., \& Hartley, J. L. 1996. "An exploration of supplier selection practices across the supply chain." Journal of Operations Management, 14(4):333-343.

Chopra, S. and Meindl, P. 2007. "Supply Chain Management. Strategy, Planning and Operation" 4th ed., Global Edition, Pearson Prentice Hall, Upper Saddle River, New Jersey

Commission Recommendation 2003/361/EC, as published in the Official Journal of the European Union L 124, p. 36 of 20 May 2003. Article 2 of the annex to Recommendation 2003/361/EC.

Corominas, A., Mateo, M., Ribas, I. and Rubio, S., 2015. "Methodological elements of supply chain design." International Journal of Production Research 53(16):5017-5030.

de Boer, L., Labro, E. and Morlacchi, P. 2001, "A review of methods supporting supplier selection", European Journal of Purchasing and Supply Management, 7(2):75-89.

Ebben, J.J. and Johnson, A.C. 2005. "Efficiency, flexibility, or both? Evidence linking strategy to performance in small firms." Strategic Management Journal 26(October 2003):1249-1259.

Ellram, L. M. 1990. "The supplier selection decision in strategic partnerships." Journal of Purchasing and materials Management, 26(4):8-14.

Eriksson, P. E. 2010. "Improving construction supply chain collaboration and performance: a lean construction pilot project." Supply Chain Management: An International Journal, 15/5:394403.

Eriksson, P. E., 2015. "Partnering in engineering projects: Four dimensions of supply chain integration." Journal of Purchasing and Supply Management, 21(1):38-50.

Eriksson, P. E., and Pesämaa, O., 2013. "Buyer-supplier integration in project-based industries." Journal of Business \& Industrial Marketing, 28(1):29-40.

Fabbe-Costes, N. and Jahre, M., 2008. "Supply chain integration and performance: a review of the evidence." The International Journal of Logistics Management 19(2):130-154.

Fawcett, S. E., McCarter, M. W., Fawcett, A. M., Webb, G. S., and Magnan, G. M. 2015. "Why supply chain collaboration fails: the socio-structural view of resistance to relational strategies." Supply Chain Management: An International Journal, 20(6):648-663.

Fisher, M.L. 1997. "What is the right supply chain for your product?" Harvard Business Review 75(2):105-116. 
Frohlich, M. T., and Westbrook, R., 2001. "Arcs of integration: an international study of supply chain strategies.” Journal of operations management, 19(2):185-200.

Gadde, L. E., and Dubois, A. 2010. "Partnering in the construction industry-Problems and opportunities.” Journal of Purchasing and Supply Management, 16(4):254-263.

Gibbert, M., and Ruigrok, W. 2010. "The" what" and" how" of case study rigor: Three strategies based on published research.” Organizational Research Methods, 13(4):710-737.

Gibbert, M., Ruigrok, W., and Wicki, B., 2008. "What passes as a rigorous case study?" Strategic management journal, 29(13):1465-1474

Goffin, K., Lemke, F., and Szwejczewski, M., 2006. “An exploratory study of 'close' suppliermanufacturer relationships.” Journal of operations management, 24(2):189-209.

Gosling, J., and Naim, M. M. 2009. "Engineer-to-order supply chain management: A literature review and research agenda.” International Journal of Production Economics, 122(2):741-754.

Gosling, J., Towill, D. R., Naim, M. M., and Dainty, A. R. 2015. "Principles for the design and operation of engineer-to-order supply chains in the construction sector." Production Planning \& Control, 26(3):203-218.

Guest, G., \& McLellan, E. (2003). "Distinguishing the trees from the forest: Applying cluster analysis to thematic qualitative data." Field Methods, 15(2), 186-201.

Hicks, C., McGovern, T., and Earl, C. F. 2000. "Supply chain management: A strategic issue in engineer to order manufacturing." International Journal of Production Economics, 65(2):179190.

Holimchayachotikul, P., Derrouiche, R., Damand, D., and Leksakul, K. 2014. "Value creation through collaborative supply chain: holistic performance enhancement road map." Production Planning \& Control, 25(11), 912-922.

Hsu, C.C., Kannan, V.R., Leong, G.K., and Tan, K.C., 2006. "Supplier selection construct: instrument development and validation." The International Journal of Logistics Management 17(2):213-239.

Ireland, P. 2004. "Managing appropriately in construction power regimes: understanding the impact of regularity in the project environment." Supply Chain Management: An International Journal, 9(5):372-382.

Kache, F., and Seuring, S. 2014. "Linking collaboration and integration to risk and performance in supply chains via a review of literature reviews." Supply Chain Management: An International Journal, 19(5/6): 664-682. 
Ketokivi, M., and Choi, T. 2014. "Renaissance of case research as a scientific method", Journal of Operations Management 32(5):232-240.

Kim, S. Y., and Nguyen, V. T. 2018. "A Structural model for the impact of supply chain relationship traits on project performance in construction." Production Planning \& Control, 29(2), 170-183.

Kirca, A.H., Roth, K., Hult, G.T.M. and Cavusgil, S.T., 2012. "The role of context in the multinationality-performance relationship: A meta-analytic review." Global Strategy Journal 2(2):108-121.

Koufteros, X., Vickery, S. K., and Dröge, C. 2012. "The effects of strategic supplier selection on buyer competitive performance in matched domains: does supplier integration mediate the relationships?." Journal of Supply Chain Management, 48(2):93-115.

Kumar, R., and Kumar Singh, R. 2017. "Coordination and responsiveness issues in SME supply chains: a review." Benchmarking: An International Journal, 24(3):635-650.

Lambert, D. M., Emmelhainz, M. A., and Gardner, J. T. 1996. "Developing and implementing supply chain partnerships." The international Journal of Logistics management, 7(2):1-18.

Lee, C. J., and Johnsen, R. E. 2012. "Asymmetric customer-supplier relationship development in Taiwanese electronics firms." Industrial Marketing Management, 41(4):692-705.

Lee, H.L. 2004. “The triple-A supply chain.” Harvard Business Review 82(10):102-12.

Lorentz, H., Töyli, J., Solakivi, T., Hälinen, H.-M., and Ojala, L. 2012. "Effects of geographic dispersion on intra-firm supply chain performance" Supply Chain Management: An International Journal, 17(6):611-626.

Macia, L. (2015). Using Clustering as a Tool: Mixed Methods in Qualitative Data Analysis. The Qualitative Report, 20(7), 1083-1094. Retrieved from http://nsuworks.nova.edu/tqr/vol20/iss 7/9

Masi, D., Micheli, G. J., and Cagno, E. 2013. "A meta-model for choosing a supplier selection technique within an EPC company." Journal of Purchasing and Supply Management, 19(1):515.

Matopoulos, A., Vlachopoulou, M., Manthou, V., and Manos, B. (2007). "A conceptual framework for supply chain collaboration: empirical evidence from the agri-food industry." Supply Chain Management: An International Journal, 12(3):177-186

Mentzer, J. T., Min, S., and Zacharia, Z. G. 2000. "The nature of interfirm partnering in supply chain management." Journal of Retailing, 76(4):549-568. 
Mello, M. H., Strandhagen, J. O., and Alfnes, E. 2015. "Analyzing the factors affecting coordination in engineer-to-order supply chain." International Journal of Operations \& Production Management, 35(7):1005-1031.

Melnyk, S. A., Narasimhan, R., and DeCampos, H. A. 2014. "Supply chain design: issues, challenges, frameworks and solutions.", International Journal of Production Research, 52(7):1887-1896.

Micheli, G.J.L., 2008. "A decision-maker-centred supplier selection approach for critical supplies.” Management Decision 46(6):918-932.

Mukherjee, K. 2014. "Supplier selection criteria and methods: past, present and future.", International Journal of Operations Research, 27(1/2):356-373.

Nyaga, G. N., Whipple, J. M., and Lynch, D. F. 2010. "Examining supply chain relationships: do buyer and supplier perspectives on collaborative relationships differ?" Journal of operations management, 28(2):101-114.

Omar, A., Davis-Sramek, B., Myers, M.B. and Mentzer, J.T., 2012. "A global analysis of orientation, coordination, and flexibility in supply chains." Journal of Business Logistics 33(2):128-144.

Palomero, S., and Chalmeta, R. 2014. "A guide for supply chain integration in SMEs." Production Planning \& Control, 25(5):372-400.

Patton, M. Q. 1990. Qualitative Research and Evaluation Methods, 2nd edn, Newbury Park, CA:Sage.

Prajogo, D., Oke, A., and Olhager, J., 2016. "Supply chain processes." International Journal of Operations \& Production Management 36(2):220-238.

Ruuska, I., Ahola, T., Martinsuo, M., and Westerholm, T. 2013. "Supplier capabilities in large shipbuilding projects." International Journal of Project Management, 31(4):542-553.

Sabri, Y., Micheli, G. J.L. and Nuur, C., 2017. "How Do Different Supply Chain Configuration Settings Impact on Performance Trade-Offs?" International Journal of Logistics Systems and Management, 26(1):34-56.

Sariola, R., and Martinsuo, M. M. 2015. "Framework for enhanced third-party relationships in project networks." International Journal of Managing Projects in Business, 8(3):457-477.

Sezen, B., 2008. "Relative effects of design, integration and information sharing on supply chain performance.” Supply Chain Management: An International Journal 13(3):233-240. 
Simatupang, T. M., and Sridharan, R., 2002. "The collaborative supply chain." The international journal of logistics management, 13(1):15-30.

Soosay, C. A., and Hyland, P. 2015. "A decade of supply chain collaboration and directions for future research.” Supply Chain Management: An International Journal, 20(6):613-630.

Spekman, R. E., 1988. "Strategic supplier selection: Understanding long-term buyer relationships." Business horizons, 31(4):75-81.

Tan, K.C., Kannan, V.J., and Handfield, R.B., 1998. "Supply chain management: supplier performance and firm performance." International Journal of Purchasing and Materials Management 34(3):2-9.

UCC-ANIMA, 2011, Report “Il Libro Bianco della Caldareria”, UCC-ANIMA, Milano, Italy.

Van der Vaart, T. and van Donk, D.P., 2008. "A critical review of survey-based research in supply chain integration." International Journal of Production Economics 111(1):42-55.

Villena, V. H., and Craighead, C. W. 2017. "On the same page? How asymmetric buyer-supplier relationships affect opportunism and performance." Production and Operations Management, 26(3):491-508.

Wagner, S.M., Grosse-Ruyken, P.T. and Erhun, F. 2012. "The link between supply chain fit and financial performance of the firm." Journal of Operations Management 30(4):340-353.

Watt, D. J., Kayis, B., and Willey, K. 2010. "The relative importance of tender evaluation and contractor selection criteria." International Journal of Project Management, 28(1):51-60.

Wetzstein, A., Hartmann, E., Benton Jr, W. C., and Hohenstein, N. O. 2016. "A systematic assessment of supplier selection literature-state-of-the-art and future scope." International Journal of Production Economics, 182, 304-323.

Yin, R.K., 2018. "Case Study Research and Applications: Design and Methods" $6^{\text {th }}$ ed., Sage Publications Inc., Thousand Oaks, CA.

Youn, S., Yang, M. G. M., Hong, P., and Park, K., 2013. "Strategic supply chain partnership, environmental supply chain management practices, and performance outcomes: an empirical study of Korean firms." Journal of Cleaner Production, 56(2013): 21-130.

Zheng, W., Yang, B. and McLean, G.N., 2010. "Linking organizational culture, structure, strategy, and organizational effectiveness: Mediating role of knowledge management." Journal of Business research 63(7):763-771. 